\title{
Hanford Beta-Gamma \\ Personnel Dosimeter \\ Prototypes and Evaluation
}

\author{
J. J. Fix \\ K. L. Holbrook \\ K. L. Soldat
}

April 1983

Prepared for the U.S. Department of Energy under Contract DE-AC06-76RLO 1830

Pacific Northwest Laboratory

Operated for the U.S. Department of Energy

by Battelle Memorial Institute 


\title{
DISCLAIMER
}

This report was prepared as an account of work sponsored by an agency of the United States Government. Neither the United States Government nor any agency thereof, nor any of their employees, makes any warranty, express or implied, or assumes any legal liability or responsibility for the accuracy, completeness, or usefulness of any information, apparatus, product, or process disclosed, or represents that its use would not infringe privately owned rights. Reference herein to any specific commercial product, process, or service by trade name, trademark, manufacturer, or otherwise, does not necessarily constitute or imply its endorsement, recommendation, or favoring by the United States Government or any agency thereof. The views and opinions of authors expressed herein do not necessarily state or reflect those of the United States Government or any agency thereof.

\author{
PACIFIC NORTHWEST LABORATORY \\ operated by \\ BATTELLE \\ for the \\ UNITED STATES DEPARTMENT OF ENERGY \\ under Contract DE-AC06-76RLO 1830
}

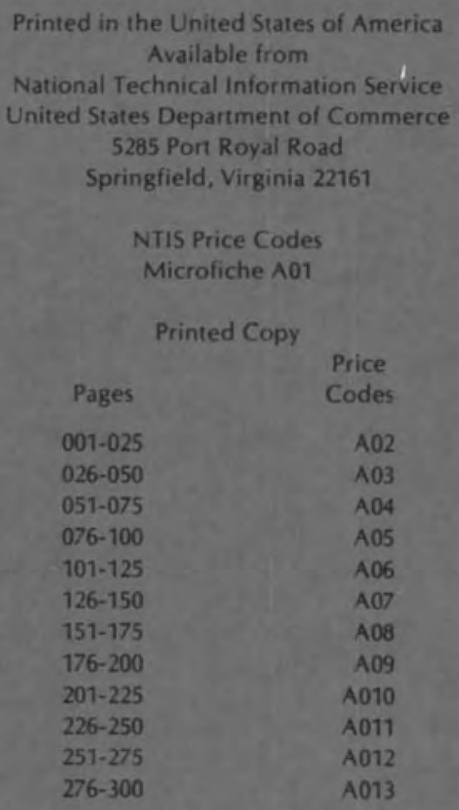


HANFORD BETA-GAMMA PERSONNEL DOSIMETER

PROTOTYPES AND EVALUATION
J. J. Fix
K. L. Holbrook
K. L. Soldat

April 1983

Prepared for

the Department of Energy

under Contract DE-ACO6-76RLO 1830

Pacific Northwest Laboratory

Richland, Washington 99352 


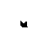


FOREWORD

Beta-gamma dosimeter prototypes, calibration procedures, and dose algorithms were developed during FY-1982 for possible use at Hanford. The dosimeters are compatible with the existing automatic reader processing system employed at Hanford and the dosimeter holder design. A neutron sensitive chip is included in all dosimeter designs to provide a response indicative of any significant neutron exposure. However, these dosimeters are not designed to be used routinely as personnel neutron dosimeters without substantial field measurements of neutron dose and spectra. A progressive technical evaluation is provided in terms of the performance of prototype dosimeters in relation to the performance of the existing Hanford beta-gamma-neutron dosimeter. 


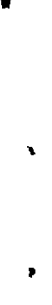




\section{SUMMARY}

Upgraded and modified Hanford dosimeter prototypes were evaluated for possible use at Hanford as a primary beta-gamma dosimeter. All prototypes were compatible with the current dosimeter card and holder design, as well as processing with the automated Hanford readers. Shallow- and deep-dose response was determined for selected prototypes using several beta sources, K-fluorescent $x$ rays and filtered $x$-ray techniques. All prototypes included a neutron sensitive chip.

A progressive evaluation of the performance of each of the upgrades to the current dosimeter is described in Section 6.0 starting with the performance of the current dosimeter. Thereafter, the performance of selected modifications of the dosimeter is presented. For each modification, a brief explanation of the steps necessary to implement it is provided.

In general, the performance of the current dosimeter can be upgraded using individual chip sensitivity factors to improve precision and an improved algorithm to minimize bias. The performance of this dosimeter would be adequate to pass al1 categories of the ANSI N13.11 performance criteria for dosimeter processors, provided calibration techniques compatible with irradiations adopted in the standard were conducted. The existing neutron capability of the dosimeter could be retained.

Better dosimeter performance to beta-gamma radiation can be achieved by modifying the Hanford dosimeter so that four of the five chip positions are devoted to calculating these doses instead of the currently used two chip positions. A neutron sensitive chip was used in the 5 th chip position, but all modified dosimeter prototypes would be incapable of discriminating between thermal and epithermal neutrons. An improved low energy beta response can be achieved for the current dosimeter and a 11 prototypes considered by eliminating the security credential. Further improvement can be obtained by incorporating the 15-mil thick TLD-700 chips.

Motivation to examine the possible implementation of a beta-gamma dosimeter is attributable in part to the fact that the vast majority of personnel exposure received at Hanford is from beta-gamma radiation and, by devoting more 
of the capability of the dosimeter to this area, better assessment of personnel doses will be achieved. Complimenting this effort would be the implementation of personnel neutron dosimeters particularly suited for the neutron dose and energy spectra being encountered by the few Hanford personnel working in neutron fields. The merits of this approach must be weighed against the cost of implementation, the actual improvement in performance obtained, the cost of administering more than one dosimeter type and the comparative technical performance obtainable by simply upgrading the current dosimeter system. 


\section{CONTENTS}

FOREWORD

i $i \mathrm{i}$

SUMMARY

ACKNOWLEDGMENTS

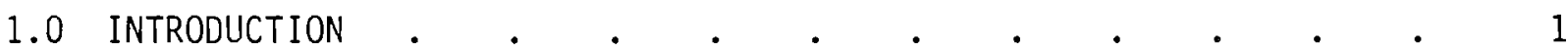

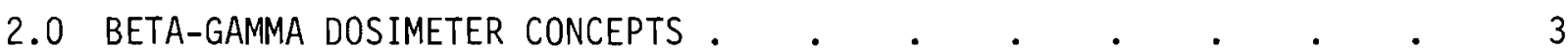

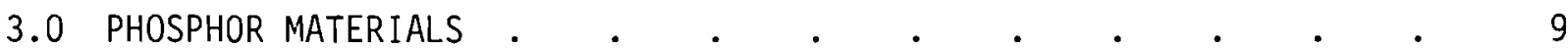

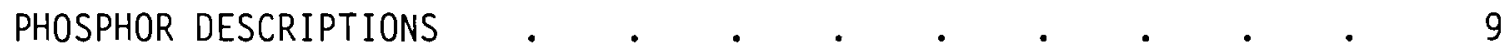

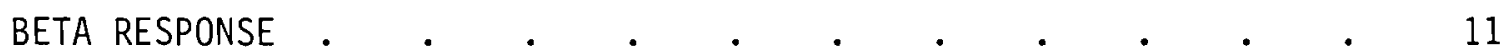

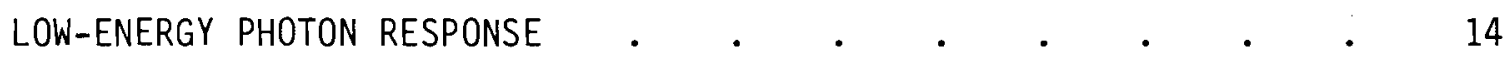

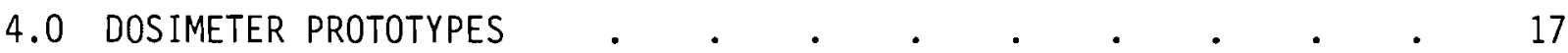

BETA-GAMMA SPECTROMETER CONCEPT $\quad$ • $\quad$ •

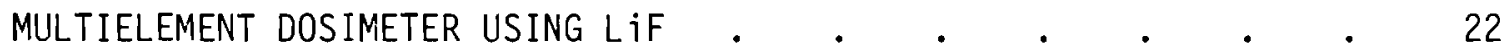

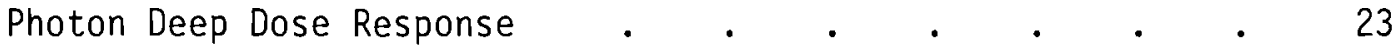

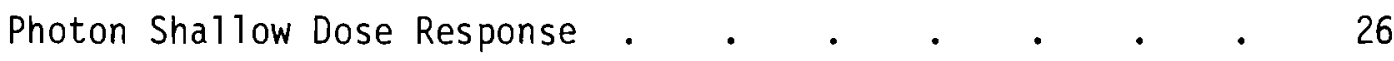

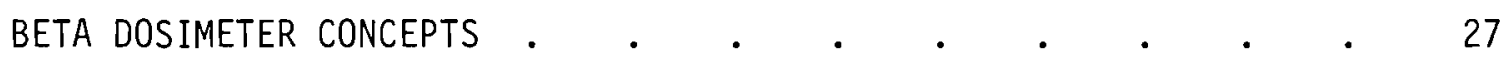

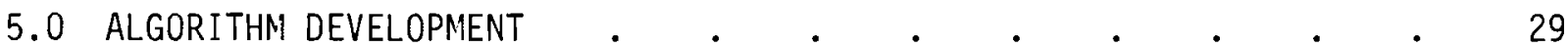

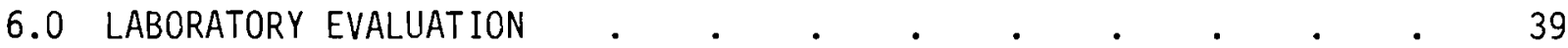

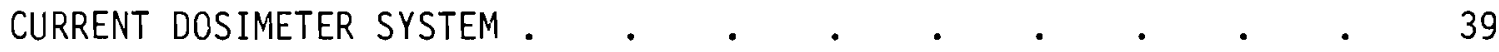

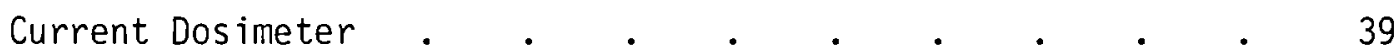

Individual Phosphor Sensitivity Factors . . . . . . 42

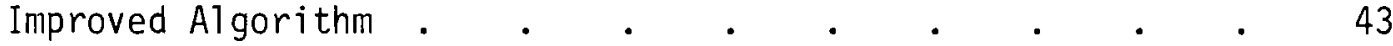

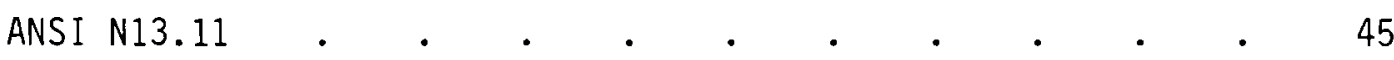

MODIFIED HANFORD DOSIMETRY DESIGNS ..$\quad \ldots \quad$. $\quad . \quad$. 47

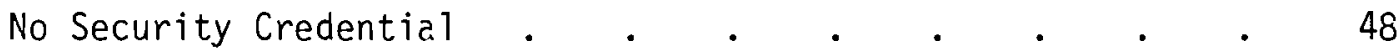

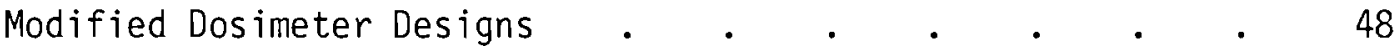




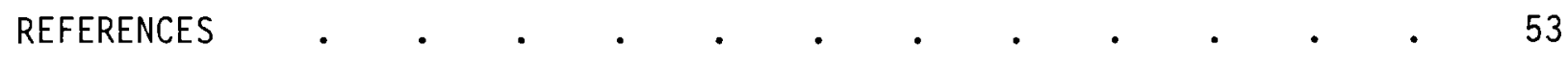

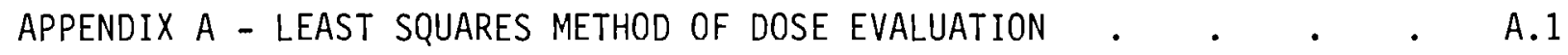




\section{FIGURES}

2.1 Percent Depth Dose in Tissue for Selected Photon Beams . $\quad$ • 4

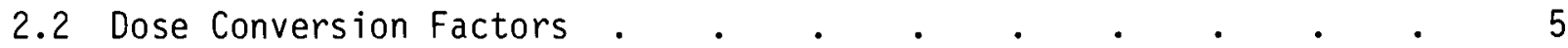

2.3 Attenuation of Photons Caused by $100 \mathrm{mg} / \mathrm{cm}^{2}$ of Polyethylene,

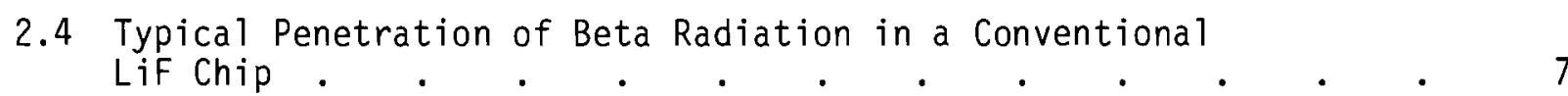

3.1 Relative Response of Phosphors to 1-Rad Shallow Dose
Irradiated On-Phantom

3.2 Relative Response of Phosphors to 1-Rad Shallow Dose
Irradiated In-Air ...
.

4.1 1-cm Dose Response of LiF:Mg Relative to ${ }^{137} \mathrm{CS}$. . . . . 23

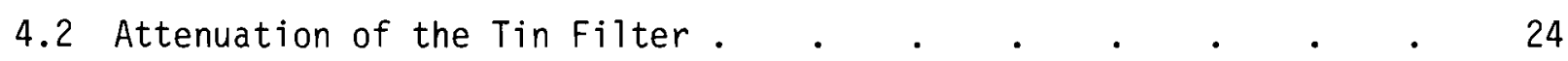

4.3 Necessary Attenuation of the Aluminum Filter . . . . . . . 25

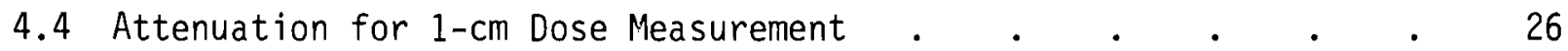

4.5 Shallow Dose Response, Relative to ${ }^{137} \mathrm{Cs}$, of Unfiltered
TLD-700 $. \quad . \quad . \quad . \quad . \quad . \quad . \quad . \quad . \quad . \quad . \quad . \quad 27$

4.6 Design of a Dosimeter to Measure Shallow Dose from Photons . . 28

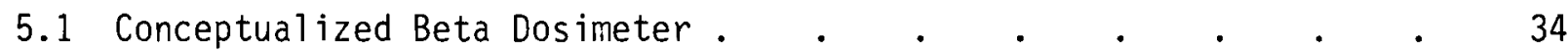

6.1 Comparison of Delivered Shallow and Reported Skin Dose

for the Hanford Dosimeter with and without the Security

Credential for Selected Nuclides . . . . . . . . 40

6.2 Comparison of Delivered and Calculated Shallow Dose Using

Existing Algorithm for Original Chip Signals and Revised Chip

Signals Based on Individual Chip Sensitivity Factors . . .

6.3 Comparison of Delivered and Calculated Deep Dose Using

Existing Algorithm for Original Chip Signals and Revised Chip

Signals Based on Individual Chip Sensitivity Factors . . . . 42

6.4 Comparison of Delivered and Calculated Shallow Dose Using

Improved Algorithm for Original Chip and Revised Chip

Signals Based on Individual Chip Sensitivity Factors 
6.5 Comparison of Delivered and Calculated Deep Dose Using

Improved Algorithm for Original Chip and Revised Chip

Signals Based on Individual Chip Sensitivity Factors

6.6 Modified Dosimeter Shallow Dose Response to K-Fluorescent and Filtered X-Ray Photons . . . . . . . . . . . . . 50

6.7 Modified Dosimeter Deep Dose Response to K-Fluorescent and Filtered $X$-Ray Photons . . . . . . . . . . . . 50

6.8 Modified Dosimeter Response to Selected Beta Emitting Nuclides . 51

\section{TABLES}

2.1 Maximum Range of Selected Beta Emitting Nuclides . . . . . 6

3.1 Phosphors Investigated for Potential Use in a

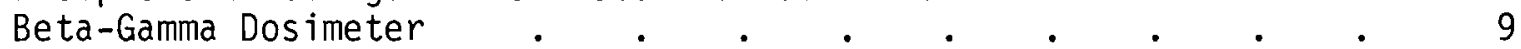

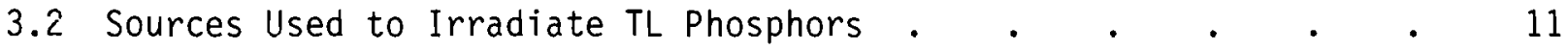

3.3 Response of TL Phosphors to Beta Radiation Exposed on Phantom in Nanocoulombs $. \quad . \quad . \quad . \quad . \quad . \quad . \quad . \quad . \quad 12$

3.4 Relative Dose 3 Response of TL Phosphors to Beta Radiation

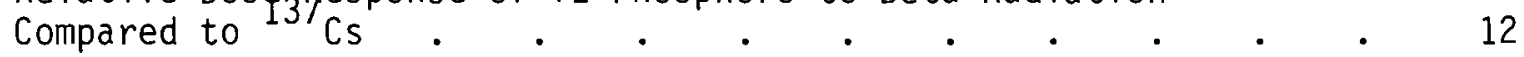

4.1 Dosimeter Prototype Using TLD-700 and TLD-400 . . . $\quad$. 18

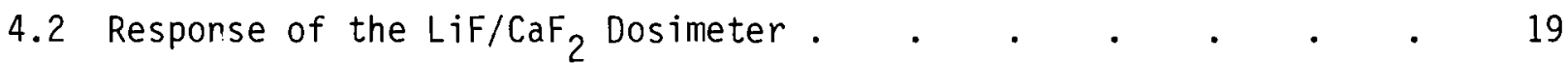

4.3 TLD Response Ratios for the $\mathrm{LiF}_{\mathrm{C}} \mathrm{CaF}$, Dosimeter . . . . . 20

4.4 Background Readings Following Reader Annealing for Unexposed
TLDs and TLDs Previously Irradiated to $500-\mathrm{mR}$

4.5 Multielement Dosimeter Design .

5.1 TLD Response for the LiF Multielement Dosimeter . . . . . 30

5.2 TLD Shallow Dose Response Relative to ${ }^{137} \mathrm{Cs}$. . . . . . 30

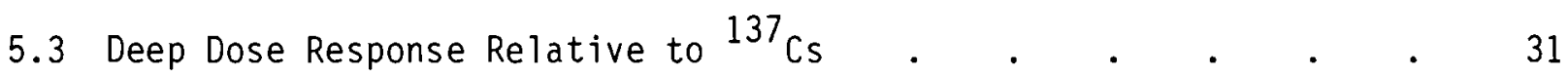

5.4 Predicted Deep Dose Response of the LiF Multielement Dosimeter . 32

5.5 Predicted Shallow Dose Response of LiF Multielement Dosimeter . 33 
5.6 Beta Algorithm Development Using Thick TLD-700 . . . . . 35

5.7 Beta Dosimetry Using Thin LiF TLD Response Relative to ${ }^{137} \mathrm{Cs}$. . 36

5.8 Chip Response Ratios for the LiF Multielement Dosimeter • • 36

5.9 Beta Photon Shallow Dose Algorithm . . . . . . . . . . . 37

6.1 ANSI N13.11 Test Categories . . . . . . . . . . . . . 46

6.2 Expected Performance of Current Dosimeter Options Relative to ANSI N13.11 Criteria $. \quad . \quad . \quad . \quad . \quad . \quad . \quad . \quad . \quad . \quad 47$ 
.

. 


\section{ACKNOWLEDGMENT}

Fred Eichner, Mark Johnson, and Virginia Tews of Pacific Northwest Laboratory, and Sheila Davis and Jerry Peters of U.S. Testing Company read the many dosimeters used during this program. Becky Hogan conducted many of the beta and $x$-ray exposures. Special acknowledgment is due Marianna Cross and Kelly Feuerbacher who typed the report and made arrangements for its eventual publication. Mary Ann Mckinney edited the report. 
,

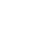




\section{HANFORD BETA-GAMMA PERSONNEL DOSIMETER \\ PROTOTYPES AND EVALUATION}

\subsection{INTRODUCTION}

The current Hanford thermoluminescent albedo type personnel dosimeter was implemented on a routine basis during January 1971. The design, calibration, readout, and dose algorithm procedures for this dosimeter allow an estimate of the nonpenetrating, penetrating, fast- and slow-neutron dose components. Numerous aspects of this system have been documented previously as BNWL-SA-3955, "The Hanford Thermoluminescent Multipurpose Dosimeter" (Kocher et al. 1971), PNL-3536, "Hanford Personnel Dosimeter Supporting Studies FY-1980" (Fix et al. 1981), and PNL-3736, "Hanford Personnel Dosimeter Supporting Studies FY-1981" (Fix et al. 1982).

The work described in this document pertains to the development of a primary beta-gamma dosimeter for possible use at Hanford. The dosimeter designs considered are compatible with the automatic reader processing and current dosimeter holder design albeit with filter and phosphor changes in some cases. Desirable dosimeter characteristics identified at the outset of this effort include the following:

- unique identification for each dosimeter card

- dosimeter historical file containing the number of readings, previous readout doses and cumulative dose

- capability to pass beta and photon categories of the ANSI N13.11 performance criteria (American National Standards Institute 1982)

- individual chip sensitivity factors

- on-phantom dosimeter calibrations

- thermal and epithermal neutron response. 
The unique dosimeter identification, chip sensitivity factors and associated historical file provide the capability of monitoring the dosimeter performance through time. Significant program decisions can be made given information regarding dosimeter response as a function of frequency of readings, cumulative dose, etc. Also, the evaluation of spurious dosimeter results would be greatly enhanced.

The recommendation for on-phantom calibrations is based on their direct comparability with personnel exposures and the ease with which personnel doses can be evaluated for differences in dosimeter response between field and laboratory radiation exposures. A neutron response was retained because of the desire to insure that no significant personnel dose would be missed by the use of this dosimeter in radiation zones involving neutrons.

Motivation to develop a primary beta-gamma dosimeter is due in part to the fact that the majority of personnel exposure at Hanford is attributable to this radiation. Devoting more of the capability of the dosimeter to this area would result in better determination of most personnel doses. A separate neutron dosimeter would be provided for the few personnel working in areas with neutron radiation in addition to the beta-gamma dosimeter. For the current five-chip dosimeter, three of the chips are used for neutron dosimetry and the remaining two chips for beta-gamma dosimetry.

Another motivation for separating the beta-gamma and neutron dosimeters is the difficulty of providing accurate personnel neutron dosimetry. The albedo dosimeter design commonly employed because of its sensitivity, such as Hanford's, has an energy response which varies by a factor of 100 between neutron energies of $10 \mathrm{keV}$ and $1 \mathrm{MeV}$ (Brackenbush et a1. 1980). Several improved techniques are currently under development as part of a DOE Headquarters funded program which will improve the field capability for personnel neutron dosimetry (Fix 1981, Parkhurst 1982). For existing dosimeters, facility calibration factors determined from field measurements are needed to extrapolate from the laboratory calibration exposure to the field conditions at each facility. When the neutron component of personnel dose is not large compared to the total dose received, many laboratories simply over-estimate the neutron dose as preferable to applying individual facility calibration factors. 


\subsection{BETA-GAMMA DOSIMETER CONCEPTS}

The dosimeter concepts considered are compatible with the existing dosimeter card and holder and automatic reader system employed at Hanford. The approach followed an evaluation of concepts progressively different from the existing system. The most significant change considered was a complete change of phosphors and filters. For several concepts the methodology of calibration and dose algorithm was considered in their evaluation.

A dosimeter design was desired with the capability of assessing tissue dose at $7 \mathrm{mg} / \mathrm{cm}^{2}$ (shallow dose) and $1000 \mathrm{mg} / \mathrm{cm}^{2}$ (deep dose). These depths correspond to the beginning of the live tissue of the skin and the beginning of organs within the body, respectively. The dosimeter response at $300 \mathrm{mg} / \mathrm{cm}^{2}$, which corresponds to the beginning of live tissue for the lens of the eye, was also of interest. However, this dose can be readily estimated from the dose at 7 and $1000 \mathrm{mg} / \mathrm{cm}^{2}$.

The tissue depth dose is very dependent upon the type and energy of the radiation incident upon the body. It is also dependent upon the size of the radiation field as well as the distance of the source from the body. Figure 2.1 illustrates the change in percent depth dose for selected photon beams for a beam size of $100 \mathrm{~cm}^{2}$ and a source to tissue distance of approximately $50 \mathrm{~cm}$ (Johns 1969).

Personnel dosimeters are generaliy calibrated to a measured dose rate. For betas, a dose is generaliy measured equivalent to a $7 \mathrm{mg} / \mathrm{cm}^{2}$ depth dose in tissue. For photons, an exposure is determined at the point of calibration and the exposure is converted to a specified dose in tissue. Figure 2.2 illustrates conversion factors for tissue depths of 7,300 , and $1000 \mathrm{mg} / \mathrm{cm}^{2}(0.007,0.3$, and $1.0 \mathrm{~cm}$, respectively) as a function of photon energy. When the dosimeter algorithms are developed, they should be capable of estimating the tissue dose at 7,300 , and $1000 \mathrm{mg} / \mathrm{cm}^{2}$ using the information illustrated in Figure 2.2 .

A problem encountered in the design of personnel dosimeters is the technique used to separate beta radiation from low-energy photons. High-energy 


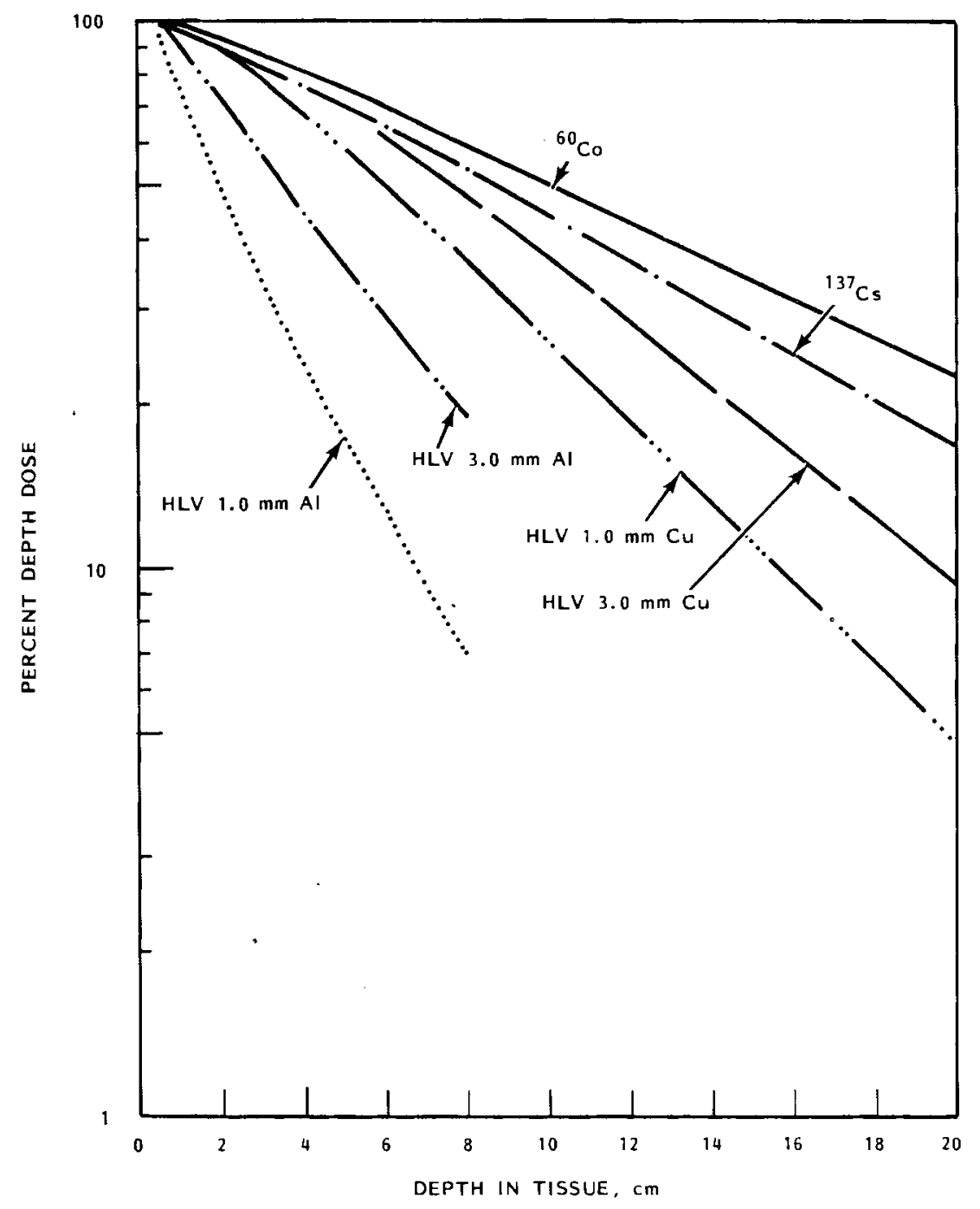

FIGURE 2.1. Percent Depth Dose in Tissue for Selected Photon Beams (Johns 1969) 


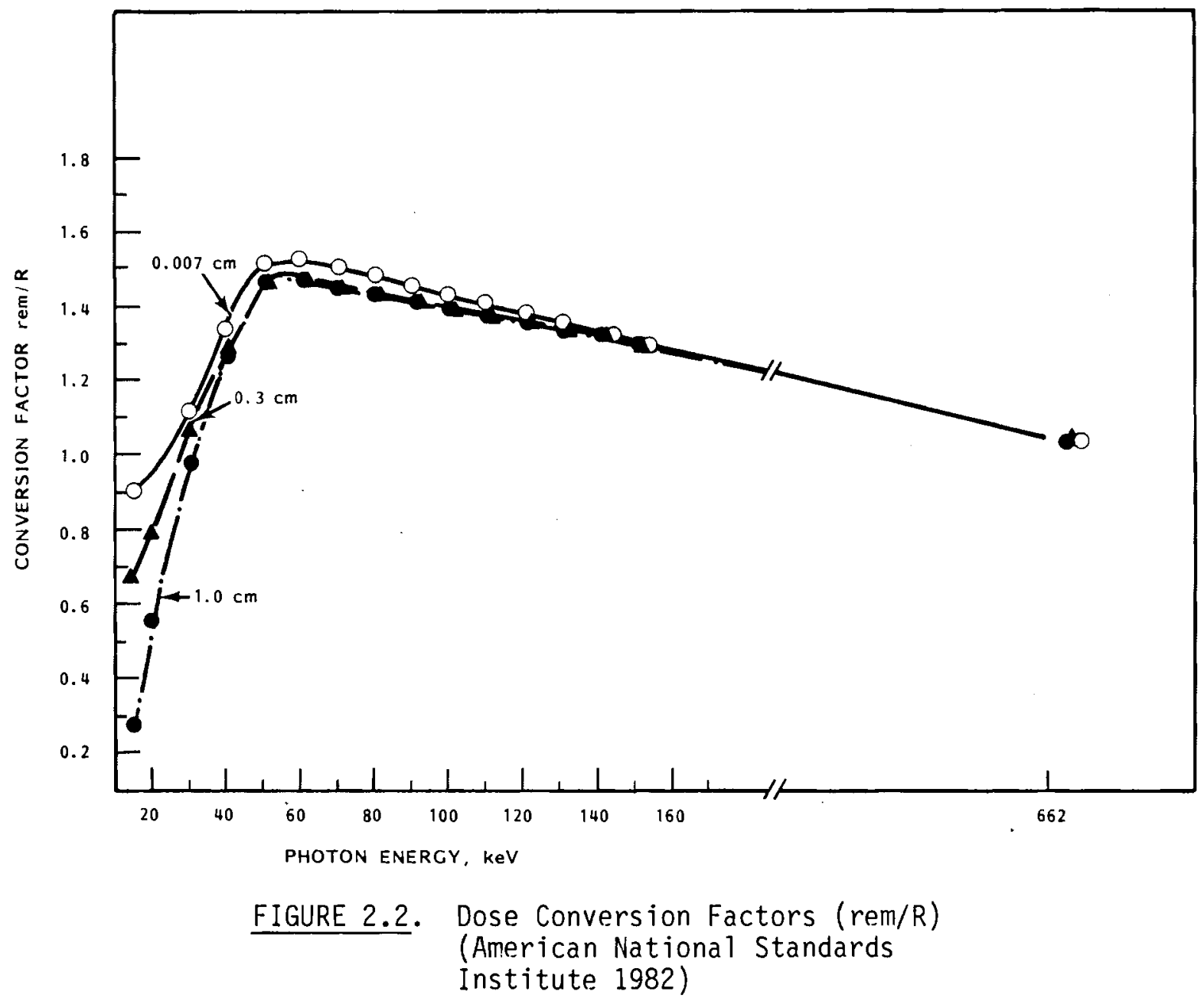

beta radiation such as from an encapsulated ${ }^{90} \mathrm{Sr} / \mathrm{Y}$ source can penetrate shielding thicknesses, such as the $365 \mathrm{mg} / \mathrm{cm}^{2}$ in the existing dosimeter used to simulate the $1-\mathrm{cm}$ depth dose, and can be confused with the $1-\mathrm{cm}$ deep dose. The maximum energy of several common beta emitting nuclides is shown in Table 2.1 along with the corresponding maximum range in $\mathrm{mg}$ per $\mathrm{cm}^{2}$ or thicknesses in $\mathrm{cm}$ for filter materials commonly used in personnel dosimeters.

The range of the beta radiation shown in Table 2.1 can be compared with the attenuation of photon radiation caused by $100 \mathrm{mg} / \mathrm{cm}^{2}$ of polyethylene, carbon, aluminum, and tin illustrated in Figure 2.3. The significant attenuation of photons caused by materials with higher atomic numbers is one method in which beta and photon induced dosimeter responses are separated. 
TABLE 2.1. Maximum Range of Selected Beta Emitting Nuclides

\begin{tabular}{|c|c|c|c|c|c|}
\hline \multirow[b]{3}{*}{ Nuclide } & \multirow{3}{*}{$\begin{array}{c}\text { Maximum } \\
\text { Energy, MeV }\end{array}$} & \multicolumn{4}{|c|}{ Maximum Range } \\
\hline & & \multirow{2}{*}{$\mathrm{mg} / \mathrm{cm}^{2}$} & \multicolumn{3}{|c|}{ Distance, $\mathrm{cm}$} \\
\hline & & & Carbon & Aluminum & Tin \\
\hline & 0.225 & 50 & 0.022 & 0.019 & 0.009 \\
\hline & 0.544 & 180 & 0.080 & 0.067 & 0.031 \\
\hline $\mathrm{kr}$ & 0.672 & 230 & 0.102 & 0.085 & 0.040 \\
\hline $90 y$ & 2.245 & 1100 & 0.488 & 0.407 & 0.190 \\
\hline${ }^{106} \mathrm{Ru}$ & 3.541 & 1800 & 0.800 & 0.667 & 0.310 \\
\hline
\end{tabular}

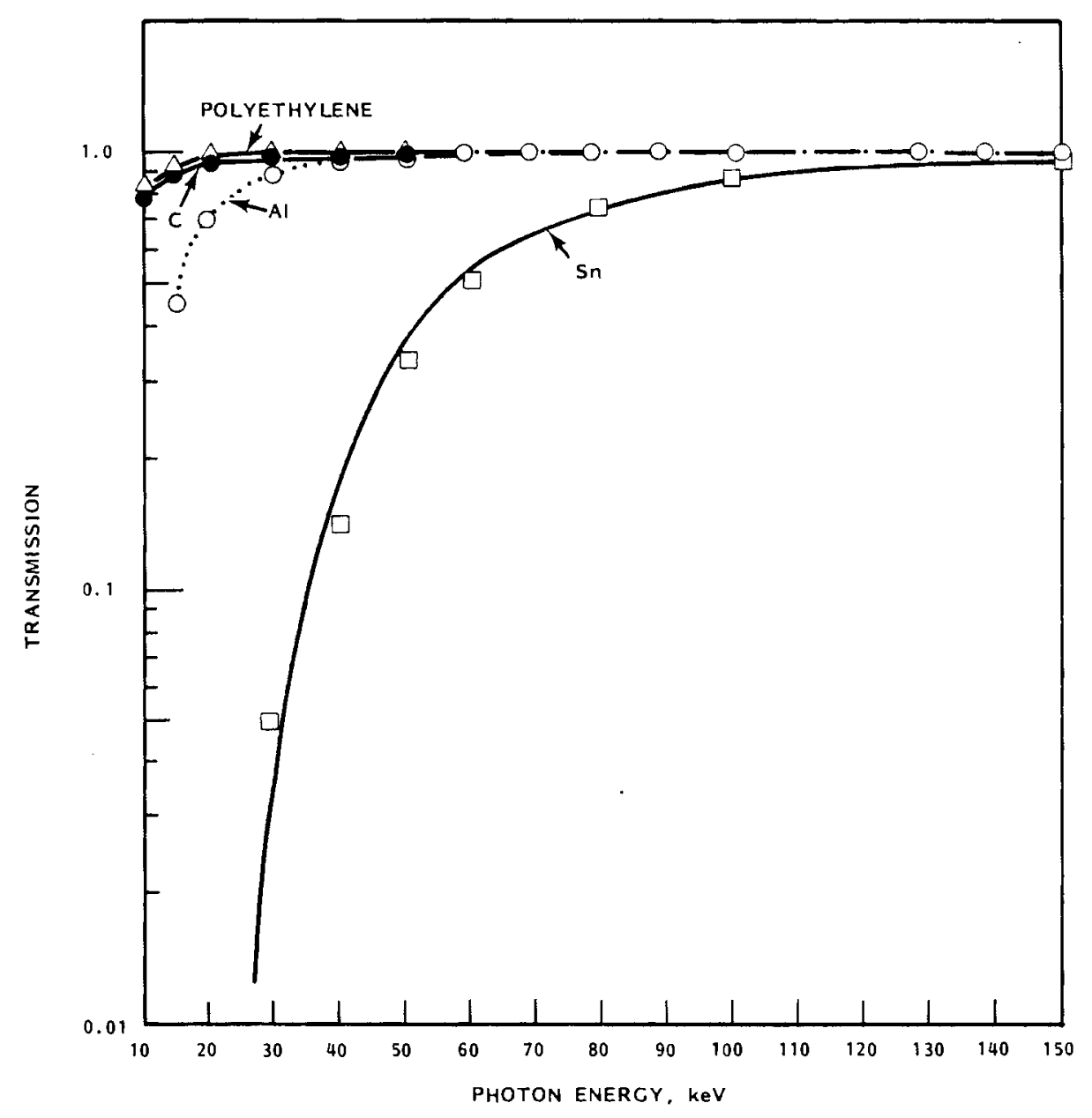

FIGURE 2.3. Attenuation of Photons Caused by $100 \mathrm{mg} / \mathrm{cm}^{2}$ of Polyethylene, Carbon, Aluminum, and Tin 
Complicating the assessment of personnel dose is the response of different phosphors to beta and photon radiation. The relative sensitivity of several phosphors is described in Section 3.0 for several nuclides of interest. The range of the beta radiation is also of interest. For example, the LiF TLD chip in the current dosimeter has a density thickness of about $235 \mathrm{mg} / \mathrm{cm}^{2}$ whereas the skin dose of interest is only $7 \mathrm{mg} / \mathrm{cm}^{2}$. This is illustrated in Figure 2.4 .

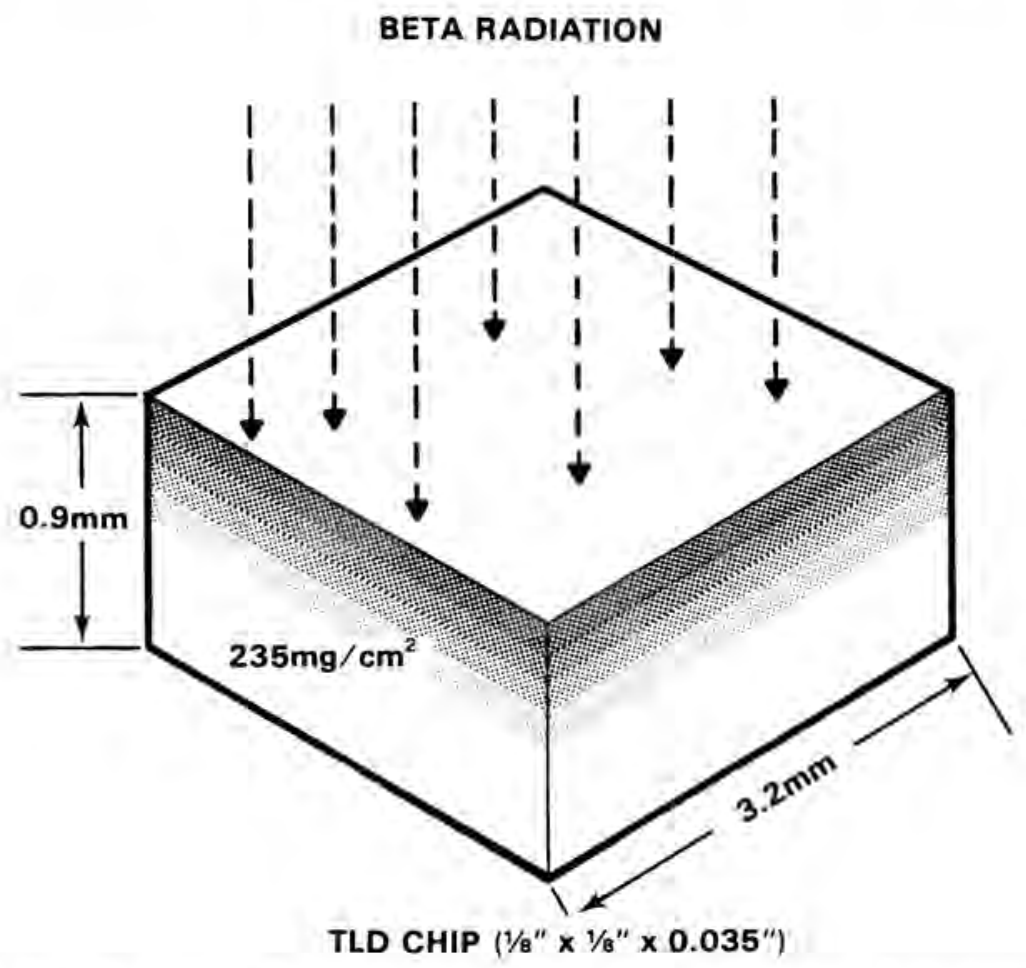

FIGURE 2.4. Typical Penetration of Beta Radiation (shaded area) in a Conventional LiF Chip 


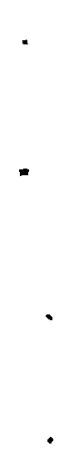




\subsection{PHOSPHOR MATERIALS}

In the preliminary design of a new beta-gamma dosimeter one of the areas under investigation was the use of different TL phosphors in the dosimeter. Using TL materials with different response characteristics may enable the user to identify the types and energies of the radiation field. The relative response of six other TL phosphors was evaluated along with the LiF phosphor currently employed in the Hanford dosimeter. Table 3.1 lists the TL phosphors evaluated.

TABLE 3.1. Phosphors Investigated for Potential Use in a Beta-Gamma Dosimeter

${ }^{7}$ LiF:Mg (currently used in Hanford dosimeter)

$7_{\text {LiF:Mg (thin chip, } 15 \text { mil) }}$

LiF:Mg (boron diffused)

$\mathrm{CaSO}_{4}$ :Dy (normal sensitivity)

$\mathrm{CaSO}_{4}:$ Dy (high surface sensitivity)

$\mathrm{CaF}_{2}: \mathrm{Mn}$

$\mathrm{MgB}_{4} \mathrm{O}_{7}: \mathrm{Dy}$

\section{PHOSPHOR DESCRIPTIONS}

A brief explanation of pertinent characteristics of each phosphor evaluated follows.

7LiF:Mg - Lithium fluoride is the most commonly used TL material. It has a density of $2.64 \mathrm{gm} / \mathrm{cc}$ and an effective atomic number $Z_{\text {eff }(L i F)}=8.14$ which is close to that of tissue, $z_{\text {eff(tissue) }}=7.42$. The main glow curve peak is at $195^{\circ} \mathrm{C}$. For most applications, it can be considered nearly tissue-equivalent but does overrespond by a factor of 1.3-1.4 at the 20-30 keV range (Mckinley 1981). ${ }^{7} \mathrm{LiF}: M g$ or TLD-700 contains $99.99 \%{ }^{7} \mathrm{Li}$ and is insensitive to neutron radiation. TLD-700 chips measuring $1 / 8^{\prime \prime}$ by $1 / 8^{\prime \prime}$ and $35 \mathrm{mil}$ in thickness are currently used in the Hanford dosimeter for beta-gamma dose evaluation. 
7 LiF:Mg (15 mil) - This phosphor is identical to the preceding phosphor except that it is only $15 \mathrm{mils}$ thick instead of $35 \mathrm{mils}$. The thinner chip is particularly useful for beta dose evaluation.

LiF:Mg (boron diffused) - This phosphor has the same chemical composition as the preceding two phosphors but contains the naturally occurring isotopic abundance of ${ }^{6} L i$ and ${ }^{7} L i$ and with boron diffused on one surface of the TLD chip. The boron diffused surface of the chip has been reported to be more sensitive to beta radiation than normal Lif (Lasky 1977).

$\mathrm{CaSO}_{4}:$ Dy - This is one of the most sensitive phosphors. It is commonly used for environmental measurements. $\mathrm{CaSO}_{4}$ doped with Dysprosium (TLD-900) has a density of $2.61 \mathrm{gm} / \mathrm{cc}$ and $Z_{\text {eff }}=15.5$. Because of its high effective atomic number it has a relatively high response to low-energy photons. At $30 \mathrm{keV}$, TLD-900s are approximately 11 times more sensitive than at the energy of ${ }^{60} \mathrm{Co}$ $\left(E_{1}=1.17 \mathrm{MeV}, \mathrm{E}_{2}=1.33 \mathrm{MeV}\right.$ ) (Oberhofer 1979). It has a relatively low response to beta radiation and is useful for discriminating low-energy photons from beta radiation in a dosimeter. The main glow curve peak occurs at $220^{\circ} \mathrm{C}$. The phosphor evaluated was in the form of pressed discs $4.5 \mathrm{~mm}$ in diameter by $0.9 \mathrm{~mm}$ thick.

$\mathrm{CaSO}_{4}:$ Dy (high surface sensitivity) - This phosphor is a relatively recent development of Harshaw Chemical Company. $\mathrm{CaSO}_{4}$ :Dy is specially treated resulting in a dual-peak glow curve with peaks at $180^{\circ} \mathrm{C}$ and $240^{\circ} \mathrm{C}$. Through proper analysis of the glow curve, both beta and low-energy photons can be evaluated. This phosphor is in the form of pressed discs identical to those in the preceding section.

$\mathrm{CaF}_{2}: \mathrm{Mn}$ - Like calcium sulphate, calcium fluoride is extremely sensitive and generally displays good TL-absorbed dose-response linearity. $\mathrm{CaF}_{2}: \mathrm{Mn}$ or $T L D-400$ has a density of $3.18 \mathrm{gm} / \mathrm{cc}$ and a $Z_{\text {eff }}=16.3$. The response at $30 \mathrm{keV}$ compared with ${ }^{60}$ Co radiation is about 15 times higher (Oberhofer 1979). The main glow curve peak is at $260^{\circ} \mathrm{C}$. The TLD-400s are in the usual chip form with dimensions of $1 / 8 \mathrm{in}$. by $1 / 8 \mathrm{in}$. by $35 \mathrm{mil}$ thick.

$\mathrm{MgB}_{4} \mathrm{O}_{7}: \mathrm{Dy}$ - This is another recently developed phosphor. It has an effective atomic number of 8.4 similar to Lif but is seven times more sensitive. The main glow curve peak occurs at $170^{\circ} \mathrm{C}$ (0berhofer 1979). It is available in disc shape with a diameter of $4.5 \mathrm{~mm}$ and a thickness of $0.7 \mathrm{~mm}$. 
These phosphors were chosen because of their sensitivity to beta-gamma radiation and their commercial availability. While other TL phosphors such as lithium borate are also sensitive to beta-gamma radiation, all commercially available lithium borate is sensitive to neutrons. To examine the response of the $T L$ phosphors, several beta and $x$-ray sources covering a wide range of energies were used. Four beta sources, ${ }^{137} \mathrm{Cs}$, plus K-fluorescent $x$ rays were used to irradiate the phosphors. These particular sources are desirable for irradiations since it is important to examine each phosphor's response to beta and low-energy photons separately. Exposures were made on- and off-phantom to account for any backscattering effects that might occur. Table 3.2 ists the sources used and their associated energies.

TABLE 3.2. Sources Used to Irradiate TL Phosphors

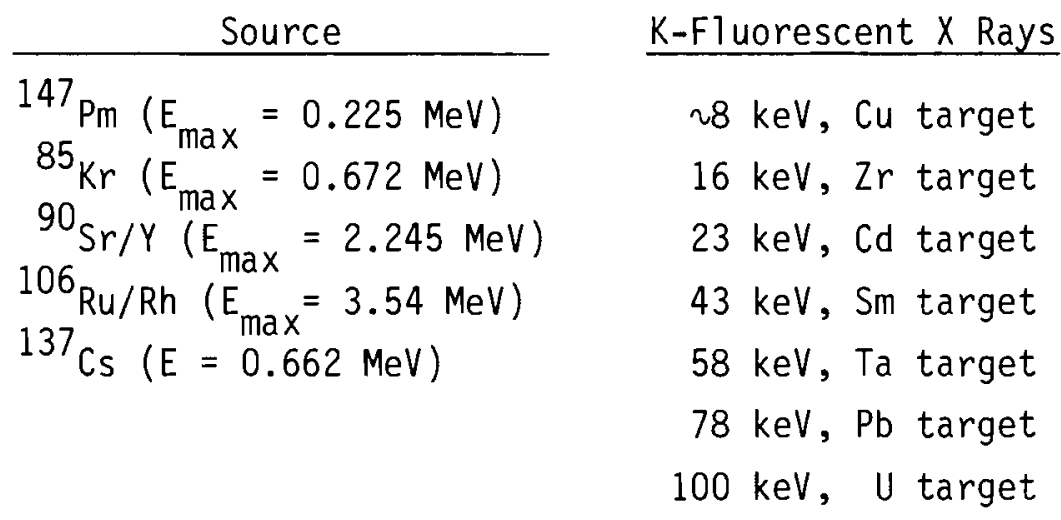

\section{BETA RESPONSE}

The TL phosphors were placed in cardboard holders behind $5 \mathrm{mils}$ $\left(15 \mathrm{mg} / \mathrm{cm}^{2}\right.$ ) of mylar which is equivalent in thickness to the Teflon encapsulation used in the current Hanford dosimeter. Twenty chips of each phosphor were exposed to 1 rad each from different beta sources to determine their relative response. Each response was compared to a dose of 1 rem from ${ }^{137}$ Cs gamma. Table 3.3 lists the response to beta radiation for each phosphor exposed on a phantom. Table 3.4 lists the relative response of each phosphor to the beta exposures compared to the ${ }^{137} \mathrm{Cs}$ response. The experiment was repeated using the same TL phosphors and exposures but done off-phantom. There was no 
TABLE 3.3. Response of TL Phosphors to Beta Radiation Exposed On-Phantom in Nanocoulombs (percent standard deviation shown in parentheses)

\begin{tabular}{|c|c|c|c|c|c|}
\hline TL Phosphor & ${ }^{137} \mathrm{Cs}$ & ${ }^{147} \mathrm{Pm}$ & ${ }^{85} \mathrm{Kr}$ & ${ }^{90} \mathrm{Sr} / \mathrm{Y}$ & ${ }^{106} \mathrm{Ru} / \mathrm{Rh}$ \\
\hline${ }^{7} \mathrm{LiF}: \mathrm{Mg}$ & 552 & 7 & 100 & 426 & 451 \\
\hline & (4) & (9) & (3) & (3) & (2) \\
\hline LiF:Mg (thin chip) & $\begin{array}{l}205 \\
(4)\end{array}$ & $(20)^{4}$ & $\begin{array}{r}75 \\
(21)\end{array}$ & 190 & 179 \\
\hline LiF:Mg (boron diffused) & 284 & 4 & 43 & 245 & 207 \\
\hline $\mathrm{CaSO}_{4}:$ Dy (normal sensitivity) & $\begin{array}{l}(10) \\
3370\end{array}$ & 52 & 905 & 2778 & $\begin{array}{l}(12) \\
2567\end{array}$ \\
\hline $\mathrm{CaSO}_{2}$ :Dy (high sensitivity) (a) & $\begin{array}{l}(28) \\
1183\end{array}$ & $\begin{array}{r}(2) \\
17\end{array}$ & $\begin{array}{r}(18) \\
429\end{array}$ & $\begin{array}{r}(36) \\
977\end{array}$ & $\begin{array}{r}(26) \\
814\end{array}$ \\
\hline 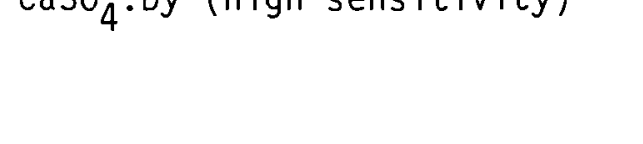 & $\begin{array}{l}(28) \\
1531 \\
(30)\end{array}$ & $\begin{array}{r}(25) \\
9 \\
(26)\end{array}$ & $\begin{array}{r}(25) \\
332 \\
(27)\end{array}$ & $\begin{array}{l}(19) \\
1267 \\
(28)\end{array}$ & $\begin{array}{l}(22) \\
1005 \\
(23)\end{array}$ \\
\hline $\mathrm{CaF}_{2}: \mathrm{Mn}$ & 2533 & 50 & 312 & 2004 & 1965 \\
\hline $\mathrm{MgB}_{4} \mathrm{O}_{7}: \mathrm{Dy}$ & $\begin{array}{r}653 \\
(17)\end{array}$ & $(25)$ & $\begin{array}{l}107 \\
137\end{array}$ & $\begin{array}{r}14) \\
510\end{array}$ & $\begin{array}{l}441 \\
(14)\end{array}$ \\
\hline
\end{tabular}

(a) Results for each peak given.

TABLE 3.4. Relative Dose Response of TL Phosphors to Beta Radiation Compared to ${ }^{137} \mathrm{Cs}$

\begin{tabular}{|c|c|c|c|c|c|}
\hline TL Phosphor & ${ }^{137} \mathrm{Cs}$ & ${ }^{147} \mathrm{Pm}$ & ${ }^{85} \mathrm{Kr}$ & ${ }^{90} \mathrm{Sr} / \mathrm{Y}$ & ${ }^{106} \mathrm{Ru} / \mathrm{Rh}$ \\
\hline${ }^{7} \mathrm{LiF}: \mathrm{Mg}$ & 1.0 & 0.02 & 0.18 & 0.79 & 0.84 \\
\hline${ }^{7} \mathrm{LiF}: \mathrm{Mg}$ (thin chip) & 1.0 & 0.02 & 0.38 & 0.96 & 0.90 \\
\hline LiF:Mg (boron diffused) & 1.0 & 0.02 & 0.15 & 0.90 & 0.75 \\
\hline $\mathrm{CaSO}_{4}:$ Dy (normal sensitivity) & 1.0 & 0.02 & 0.28 & 0.84 & 0.78 \\
\hline $\mathrm{CaSO}_{4}$ :Dy (high sensitivity) ${ }^{(a)}$ & 1.0 & 0.02 & 0.37 & 0.85 & 0.71 \\
\hline & 1.0 & 0.01 & 0.23 & 0.85 & 0.68 \\
\hline $\mathrm{CaF}_{2}: \mathrm{Mn}$ & 1.0 & 0.02 & 0.13 & 0.81 & 0.80 \\
\hline $\mathrm{MgB}_{4} \mathrm{O}_{7}: \mathrm{Dy}$ & 1.0 & 0.01 & 0.22 & 0.80 & 0.70 \\
\hline
\end{tabular}

(a) Results for each peak given. 
discernible difference between the off-phantom and on-phantom exposure data possibly attributable to the backing material of the phosphors containing the phosphors.

The low-energy beta radiation from ${ }^{147} \mathrm{Pm}$ yielded an extremely low response of $1-2 \%$ of the ${ }^{137} \mathrm{Cs}$ response in a11 the TL phosphors examined. Assuming $E_{\text {avg }}$ $=1 / 3 \mathrm{E}_{\max }$ the average beta energy from ${ }^{147} \mathrm{Pm}$ is $75 \mathrm{keV}$. Therefore the low response is expected since $5 \mathrm{mil}$ of mylar $\left(15 \mathrm{mg} / \mathrm{cm}^{2}\right)$ will attenuate all beta radiation below $100 \mathrm{keV}$. The beta energy from the ${ }^{85} \mathrm{Kr}$ yielded a response in the TL phosphors ranging from $13 \%$ to $37 \%$ of the ${ }^{137} \mathrm{Cs}$ response. The higher energy beta sources of ${ }^{90} \mathrm{Sr} / \mathrm{Y}$ and ${ }^{106} \mathrm{Ru} / \mathrm{Rh}$ gave responses of $70 \%$ to $90 \%$ of the ${ }^{137}$ Cs response.

The TL phosphors with the highest response to beta radiation were the 15-mil-thick ${ }^{7} \mathrm{LiF}: \mathrm{Mg}$ and the surface sensitive $\mathrm{CaSO}_{4}:$ Dy. For the ${ }^{85} \mathrm{Kr}$ irradiation these two phosphors responded about a factor of two higher than the remaining phosphors. The $\mathrm{TL}$ phosphors showing the best precision were the following: the currently used ${ }^{7} \mathrm{LiF}: \mathrm{Mg}$, the 15-mil-thick ${ }^{7} \mathrm{LiF}: \mathrm{Mg}$, the boron diffused $L i F$, and the $\mathrm{CaF}_{2}: M n$. Upon examining the TL phosphors during readout, it was apparent that many of them were losing their structural integrity. The disc-shaped phosphors ( $\mathrm{CaSO}: \mathrm{Dy}$ and $\mathrm{MgB}_{4} \mathrm{O}_{7}$ ) were crumbling and could not survive routine TLD processing. These phosphors showed the highest variability and of course extremely poor reproducibility.

Another problem with some of the phosphors is that they exhibit relatively high fade rates. While LiF has a negligible fade rate of less than $5 \%$ over a year, a value of $8 \%$ over 6 months has been observed for CaS0:Dy (Harshaw 1976). Our own studies ( $\mathrm{Fix} 1978$ ) show a fade rate of $10 \%$ over 30 days for $\mathrm{CaF}_{2}: \mathrm{Mn}$. $\mathrm{MgB}_{4} \mathrm{O}_{7}$ has demonstrated a fade rate of $10 \%$ over 60 days (Oberhofer 1979).

The presence of boron in $\mathrm{MgB}_{4} \mathrm{O}_{7}$ and the boron-diffused LiF phosphors make these phosphors sensitive to thermal neutrons. To determine the sensitivity, both phosphors were exposed to $200 \mathrm{mrem}$ from the $\mathrm{D}_{2} 0$-moderated ${ }^{238}$ PuBe source and found to be very sensitive to thermal neutrons and thus unacceptable for our purposes.

Based on the aforementioned parameters (integrity, precision, fade characteristics, neutron sensitivity and beta response), the 15-mil-thick ${ }^{7} \mathrm{LiF}: \mathrm{Mg}$ 
and $\mathrm{CaF}_{2}: \mathrm{Mn}$ phosphors were determined to be the most favorable. Therefore, only these two phosphors were examined in the low-energy $x$-ray response study.

\section{LOW-ENERGY PHOTON RESPONSE}

The low-energy photon response of the LiF chips and the $\mathrm{CaF}_{2}$ :Mn chips was studied using $\mathrm{K}$-fluorescent $x$ rays. Ten chips of each phosphor were placed in cardboard packets covered by $5 \mathrm{mils}$ of mylar as in the beta exposures. Each packet of chips was then exposed to one of the energies from the $k-f l u o r e s c e n t$ $x$ rays listed in Table 3.2. The uranium filter used to provide $100-k e V \times$ rays showed signs of possible contamination and yielded inaccurate exposures. Therefore, the 100-keV data point was omitted.

Figure 3.1 shows the relative dose responses of the $\mathrm{LiF}$ and the $\mathrm{CaF}_{2}: \mathrm{Mn}$ phosphors to the low-energy $x$-ray exposures on-phantom. The response of each phosphors was normalized to ${ }^{137} \mathrm{Cs}$ irradiations on-phantom. As expected the $\mathrm{CaF}_{2}$ with a $Z=16.3$ responded high at these 10 w energies with a maximum observed at $43 \mathrm{keV}$. The 15-mil-thick ${ }^{7} \mathrm{LiF}: \mathrm{Mg}$ with a $Z=8.2$ had a response approximately a factor of 2.4 less than the 35-mil-thick chip consistent with

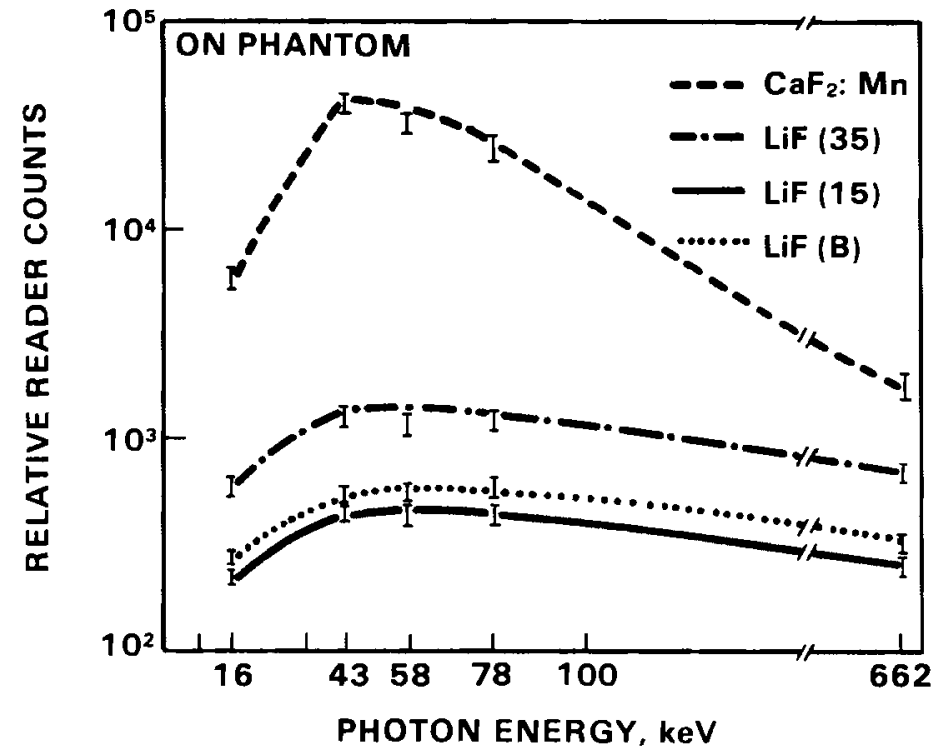

FIGURE 3.1. Relative Dose of Phosphors to 1-Rad Shallow Dose Irradiated On-Phantom 
the difference in their mass. The $k$-fluorescent $x$-ray exposures were repeated using the same phosphors in air (off-phantom). As expected the response of both phosphors decreased noticeably. Figure 3.2 shows a plot of the off-phantom exposure responses for each phosphor. The phosphors were normalized to ${ }^{137} \mathrm{Cs}$ exposures done in free air. As evidenced in the graph a slightly lower response was observed for each phosphor because of the elimination of any backscatter from the phantom.

Both the LiF and $\mathrm{CaF}_{2}$ :Mn phosphors could be used in a beta-gamma dosimeter design. The thin LiF phosphor would be desirable in a single-phosphor-design dosimeter since it demonstrates minimal energy dependence to gamma-rays. The $\mathrm{CaF}_{2}:$ Mn phosphor would be appropriate in a spectrometer-type of dosimeter since it shows a high response to $x$ rays.

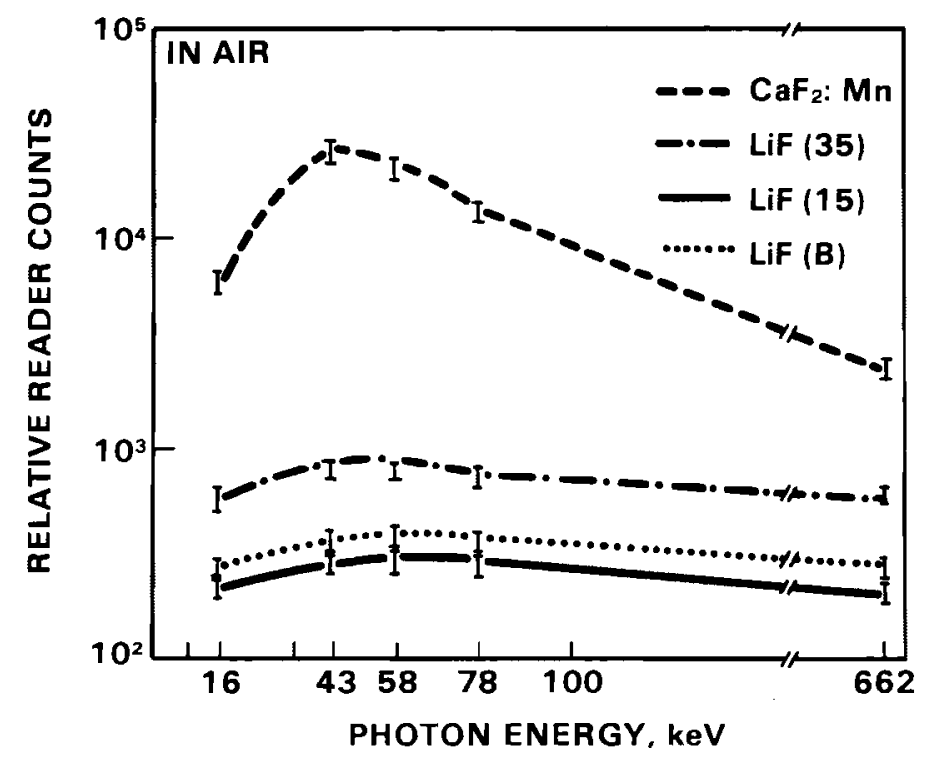

FIGURE 3.2. Relative Response of Phosphors to 1-Rad Shallow Dose Irradiated In-Air 



\subsection{DOSIMETER PROTOTYPES}

Prototype designs were selected to provide an accurate assessment of dose in tissue at specified depths. Dosimeter designs are compatible with the current Hanford system that uses four conventional TLD chips for beta-gamma measurement, with a TLD-600 in the fifth position as a neutron indicator. Use of a dosimeter holder without a security credential is assumed in the evaluation because of its significant attenuation of low-energy beta radiation. A 0.5-mil aluminized mylar shield is recommended to minimize exposure of the open window to light.

Two general designs were investigated. The first uses two TL materials with different response characteristics to identify types and energies of radiation present. The dosimeter functions as a spectrometer, and the TLD response is adjusted accordingly. The second design utilizes a single TL material and careful selection of filter materials to compensate for TLD overresponse to low-energy $x$-rays. Filters of varying atomic number are used to distinguish between beta and photon exposures. Doses are calculated based on the combined responses of each element.

A low sensitivity to neutrons is required for $T L$ materials in beta-gamma dosimeters. The single-phosphor design requires a $T L$ material with minimal energy dependence to $x$ rays. Lithium borate is nearly tissue equivalent in response; however, commercially produced chips are sensitive to neutrons. Lithium fluoride (TLD-700) is an acceptable phosphor with a moderate energy dependence to $x$ rays. For the spectrometer-type dosimeter, a high response to $x$ rays is desired. Phosphors such as $\mathrm{CaSO}_{4}:$ Dy and $\mathrm{CaF}_{2}: \mathrm{Mn}$ are suitable. The signal from a TLD-700 is used as the primary dose indication. An energyresponse correction is applied, based on the signal from $\mathrm{CaSO}_{4}$ or $\mathrm{CaF}_{2}$.

\section{BETA-GAMMA SPECTROMETER CONCEPT}

Calcium sulfate at first seemed to be an ideal material for an energy indicator. It has an extremely high response to low-energy $x$ rays. The relative signals of $\mathrm{CaSO}_{4}$ :Dy and ${ }^{7} \mathrm{LiF}: \mathrm{Mg}$ chips covered by the same attenuating material would effectively quantify the photon energies present. The photon 
dose would be based on signals from the TLD-700 with a response adjustment based on the relative signals of the LiF and $\mathrm{CaSO}_{4}$ TLDs. Thin LiF (15 mil) or conventional TLD-700 ( $35 \mathrm{mil})$ chips could be used in the open window position with a minimum amount of filtration. The beta particle energy could be determined from the relative penetration to the open window and filtered TLD-700s, after correction for photon-induced response.

During testing, two difficulties were encountered. Commercial $\mathrm{CaSO}_{4}: \mathrm{Dy}$ elements showed high variability, with sensitivities differing by as much as $50 \%$. Sensitivity problems can be overcome through use of individual chip sensitivity factors and careful screening. However, when fabricated into standard Hanford dosimeter inserts, the $\mathrm{CaSO}_{4}$ discs were crushed by the reader's hot prod and partially dissolved by the cleaning process. Degeneration continued through each successive readout.

An alternate material, $\mathrm{CaF}_{2}: \mathrm{Mn}(\mathrm{TLD}-400)$, was investigated to replace $\mathrm{CaSO}_{4}$. The chips resemble TLD-700s in appearance but have a high response to low-energy photons. During short-term testing, the chips showed minimal wear. A holder was designed to test the spectrometer concept for beta-gamma dosimetry. The design is summarized in Table 4.1. In the final design, a thin Lif TLD could be used in the open window position to allow better discrimination of low-energy betas.

TABLE 4.1. Dosimeter Prototype Using TLD-700 and TLD-400

Element Number

1

2

3

4

$5^{(a)}$
Nominal Filtration

"Open window" (no credential)

$75-\mathrm{mg} / \mathrm{cm}^{2} \mathrm{Al}+93-\mathrm{mg} / \mathrm{cm}^{2}$ plastic

$75-\mathrm{mg} / \mathrm{cm}^{2} \mathrm{Al}+57-\mathrm{mg} / \mathrm{cm}^{2}$ plastic

$408-\mathrm{mg} / \mathrm{cm}^{2} \mathrm{Sn}+57-\mathrm{mg} / \mathrm{cm}^{2}$ plastic

$408-\mathrm{mg} / \mathrm{cm}^{2} \mathrm{Cd}+57-\mathrm{mg} / \mathrm{cm}^{2}$ plastic
TLD Material

LiF:Mg (TLD-700) $15 \mathrm{mils}$ or $35 \mathrm{mils}$

$\mathrm{CaF}_{2}: \mathrm{Mn}(\mathrm{TLD}-400)$

LiF:Mg (TLD-700)

$\mathrm{CaF}_{2}: \mathrm{Mn}(\mathrm{TLD}-400)$

LiF:Mg (TLD-600)

(a) Neutron responding chip. 
Prototype $\mathrm{LiF} / \mathrm{CaF}_{2}$ dosimeters were exposed to $500 \mathrm{mR}{ }^{137} \mathrm{Cs}$ for screening, and read after a three-day holding period. Considerable difficulties were experienced with the readout process. Dosimeter inserts were reader annealed three times after normal processing. TLD background for the $\mathrm{CaF}_{2}$ remained high, with no noticeable reduction after successive readouts.

Dosimeters were re-exposed to ${ }^{137} \mathrm{Cs}$, five $\mathrm{K}$-fluorescent $x$-ray energies, two heavily filtered $x$-ray techniques and three beta sources. Four dosimeters were exposed for each energy. All irradiations included backscatter from a phantom. The TLD signal was corrected for background and normalized for individual chip sensitivity (sensitivity factors are discussed in Section 6.0). Response data are summarized in Table 4.2 .

TABLE 4.2. Response of the $L i F / \mathrm{CaF}_{2}$ Dosimeter (a)

\begin{tabular}{|c|c|c|c|c|c|}
\hline \multirow[b]{2}{*}{ Source } & \multirow[b]{2}{*}{ Irradiation } & \multicolumn{4}{|c|}{ TLD Readings, Reader Counts } \\
\hline & & Position 1 & Position 2 & Position 3 & Position 4 \\
\hline${ }^{137} \mathrm{Cs}$ & $1 \mathrm{R}$ & $1773 \pm 75$ & $1827 \pm 144$ & $709 \pm 127$ & $1853 \pm 74$ \\
\hline $16 \mathrm{keV}$ & $1 \mathrm{R}$ & $2111 \pm 229$ & $1885 \pm 524$ & $192 \pm 49$ & $1146 \pm 60$ \\
\hline $34 \mathrm{keV}$ & $1 \mathrm{R}$ & $2863 \pm 444$ & $11174 \pm 727$ & $1762 \pm 290$ & $2814 \pm 223$ \\
\hline $43 \mathrm{keV}$ & $1 \mathrm{R}$ & $3775 \pm 128$ & $12762 \pm 1156$ & $2402 \pm 79$ & $3310 \pm 155$ \\
\hline $58 \mathrm{keV}$ & $0.5 \mathrm{R}$ & $1660 \pm 122$ & $6454 \pm 1631$ & $1768 \pm 386$ & $1754 \pm 98$ \\
\hline $78 \mathrm{keV}$ & $0.5 \mathrm{R}$ & $1567 \pm 70$ & $5247 \pm 543$ & $1843 \pm 248$ & $1631 \pm 80$ \\
\hline $\begin{array}{l}\text { HFG } \\
(117 \mathrm{keV})\end{array}$ & $0.5 \mathrm{R}$ & $1077 \pm 65$ & $1741 \pm 322$ & $886 \pm 185$ & $1134 \pm 48$ \\
\hline $\begin{array}{l}\text { HFI } \\
(167 \mathrm{keV})\end{array}$ & $0.5 \mathrm{R}$ & $1069 \pm 37$ & $904 \pm 190$ & $623 \pm 129$ & $1094 \pm 14$ \\
\hline $85 \mathrm{Kr}$ & 1.01 rem & $377 \pm 16$ & - & - & - \\
\hline${ }^{90}$ Sr sphere & $1.00 \mathrm{rem}$ & $1251 \pm 72$ & $242 \pm 58$ & $30 \pm 18$ & $782 \pm 46$ \\
\hline${ }^{90} \mathrm{Sr}$ disc & 1.00 rem & $1453 \pm 39$ & $406 \pm 125$ & $50 \pm 36$ & $1001 \pm 56$ \\
\hline
\end{tabular}

(a) One standard deviation shown. 
Photon and beta energies can be distinguished using chip signal ratios. TLD readings for each position are normalized to $1-$ rem ${ }^{137} \mathrm{Cs}$. The ratios of the normalized chip signals are compared in Table 4.3. Uncertainty in distinguishing between energies will be experienced due to the high $\mathrm{CaF}_{2}$ variability.

TABLE 4.3. TLD Response Ratios for the $\mathrm{LiF} / \mathrm{CaF}_{2}$ Dosimeter

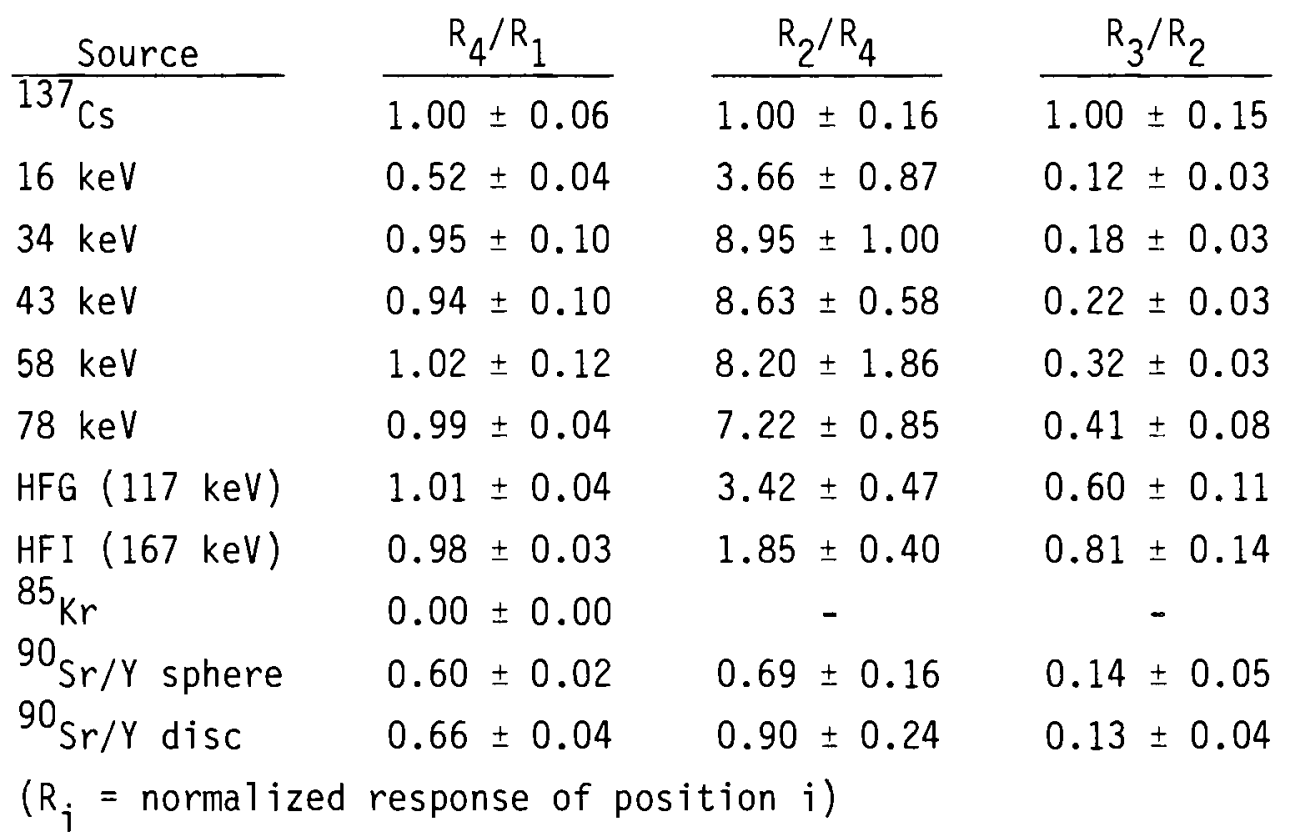

The observed background for the $\mathrm{CaF}_{2}: \mathrm{Mn}$ TLDs was extremely high. Background signals for unexposed $\mathrm{CaF}_{2}$ TLDs differed considerably from the $\mathrm{CaF}_{2}$ exposed to $500-\mathrm{mR}{ }^{137} \mathrm{Cs}$. The average TLD signals for two unexposed TLDs and three exposed TLDs are given in Table 4.4. Unexposed TLDs were read with the ${ }^{137}$ Cs screening run. The unexposed and previously exposed TLDs were read after a 20-day holding period.

The significant increase in background signal and large variability in $\mathrm{CaF}_{2}$ signal for dosimeters exposed to photons and betas can be attributed to the current Hanford readout process. The main glow peak of $\mathrm{CaF}_{2}: \mathrm{Mn}$ has an activation temperature of $300^{\circ} \mathrm{C}$. A readout temperature of $300^{\circ} \mathrm{C}$ is sufficient for processing TLD-400s if the heating period is long enough to anneal the TLDs. Heating times of 45 to 60 seconds are recommended by Harshaw Chemical 
TABLE 4.4. Background Readings Following Reader Annealing for Unexposed TLDs and TLDs Previously Irradiated to $500-\mathrm{mR} 137 \mathrm{Cs}$

\begin{tabular}{|c|c|c|c|c|}
\hline & $\begin{array}{l}\text { Position } 1 \\
\quad(\text { LiF) }\end{array}$ & $\begin{array}{l}\text { Position } \\
\left(\mathrm{CaF}_{2}\right) \\
\end{array}$ & $\begin{array}{l}\text { Position } \\
\left(\mathrm{CaF}_{2}\right) \\
\end{array}$ & $\begin{array}{l}\text { Position } 4 \\
\quad(\text { LiF) }\end{array}$ \\
\hline $\begin{array}{l}\text { Unirradiated TLDs } \\
\text { (reader counts) }\end{array}$ & $24 \pm 5$ & $18 \pm 1$ & $14 \pm 2$ & $17 \pm 3$ \\
\hline $\begin{array}{l}\text { Previously Irradiated } \\
\text { TLDs (reader counts) }\end{array}$ & $25 \pm 9$ & $95 \pm 26$ & $76 \pm 17$ & $25 \pm 7$ \\
\hline
\end{tabular}

Company. During the current Hanford read cycle, each TLD is heated for 20 seconds, with chip temperatures falling below $300^{\circ} \mathrm{C}$. The heater temperature can be adjusted, but the readout temperature is limited by the Tefion in the dosimeter insert. Acceptable Teflon substitutes have been documented which would allow heating temperatures of $315^{\circ} \mathrm{C}$ during readout ( $\mathrm{Fix}$ et al. 1981). Longer heating periods may be necessary even if heater temperatures are increased.

Other forms of $\mathrm{CaF}_{2}$, such as $\mathrm{CaF}_{2}:$ Dy (TLD-200) and $\mathrm{CaF}_{2}: \mathrm{Tm}$, are commercially available. Both phosphors exhibit a high response to low-energy photons. Glow peaks in $\mathrm{CaF}_{2}: \mathrm{Tm}$ are observed at $150^{\circ} \mathrm{C}$ and $250^{\circ} \mathrm{C}$; however, the $250^{\circ} \mathrm{C}$ peak has been found to exhibit a high sensitivity to fast neutrons and pronounced supralinearity (Lakshmanan 1982). The $\mathrm{CaF}_{2}$ :Dy main glow peaks are found at $200^{\circ} \mathrm{C}$ and $240^{\circ} \mathrm{C}$. This phosphor also shows a sensitivity to fast neutrons and a significant fade rate.

Based on the characteristics of the phosphors investigated, the spectrometer design employing LiF and a high sensitivity phosphor does not appear to be suitable for the Hanford system. The main difficulties experienced with $\mathrm{CaF}_{2}: \mathrm{Mn}$ were high variability during readout, difficulty with annealing and a significant fading problem (Fix 1978). A design utilizing only LiF is more feasible for the existing card and reader design. 
MULTIELEMENT DOSIMETER USING LiF

A multielement dosimeter with only ${ }^{7} \mathrm{LiF}: \mathrm{Mg}$ can be used to assess shallow and deep dose for all photon energies commonly encountered in the field. The dosimeter differs from a spectrometer design where the effective photon energy is determined based on chip signal ratios. The intent of the multielement LiF dosimeter is to assess dose from monoenergetic photons or any mixture of energies using a single calculation for each depth of interest in tissue. This is possible through careful selection of attenuating materials in the dosimeter holder, using the responses of several positions. Beta and photon doses are calculated independently. The dosimeter design is discussed in the following sections.

A dosimeter configuration based on calculations for shallow and deep dose response is described in Table 4.5. TLD-700 chips are used in positions 1 through 4 and a TLD-600 ( $\left.{ }^{6} \mathrm{LiF}: \mathrm{Mg}\right)$ is used in position 5 to indicate possible neutron irradiation. Filter materials are very similar to those used in the current dosimeter and holder.

Photon dose is calculated from positions 3 and 4 . The large filtration over each of the two positions is sufficient to attenuate most of the highenergy beta component from ${ }^{90} \mathrm{Sr} / \mathrm{Y}$. Beta doses are calculated from positions 1

\section{TABLE 4.5. Multielement Dosimeter Design}

Position

1

2

3

4

${ }_{5}(e)$
Filtration

$$
\begin{aligned}
& \text { Open window; } 10-\mathrm{mg} / \mathrm{cm}^{2} \text { Teflon (TLD-700) } \\
& 75-\mathrm{mg} / \mathrm{cm}^{2} \mathrm{Al}(\mathrm{a})+93-\mathrm{mg} / \mathrm{cm}^{2} \text { plastic (b) }(\text { TLD-700) } \\
& 408-\mathrm{mg} / \mathrm{cm}^{2} \mathrm{Sn}(\mathrm{c})+57-\mathrm{mg} / \mathrm{cm}^{2} \text { plastic (b) } \\
& \text { (TLD-700) } \\
& 75-\mathrm{mg} / \mathrm{cm}^{2} \mathrm{Al}^{(\mathrm{a})}+368-\mathrm{mg} / \mathrm{cm}^{2} \text { plastic (d) } \\
& \text { (TLD-700) } \\
& 408-\mathrm{mg} / \mathrm{cm}^{2} \mathrm{Cd}+57-\mathrm{mg} / \mathrm{cm}^{2} \text { Al (TLD-600) }
\end{aligned}
$$

(a) Type 1100-0 aluminum (99\%). The most significant impurity

(b) ABS plastic, $0.98 \mathrm{~g} / \mathrm{cm}^{3}$, holder thickness.

(c) Tin used in dosimeter fabrication $_{2}$ is $99.7 \%$ pure.

(d) $57-\mathrm{mg} / \mathrm{cm}^{2}$ ABS plastic $+311-\mathrm{mg} / \mathrm{cm}^{2}$ polyethylene.

(e) TLD-600 chip was not included in the beta-gamma evaluation. 
and 2 using the signal from position 4 to subtract the photon component. Holder thicknesses were based on the attenuation required to compensate for the energy dependence of LiF:Mg. The calculations for deep dose $(1 \mathrm{~cm})$ and shallow dose $(0.007 \mathrm{~cm})$ response in tissue are discussed in the remainder of this section. Photon Deep Dose Response

The response of an unfiltered TLD-700 irradiated on the phantom is shown in Figure 4.1. Information is based on the response of Hanford dosimeters

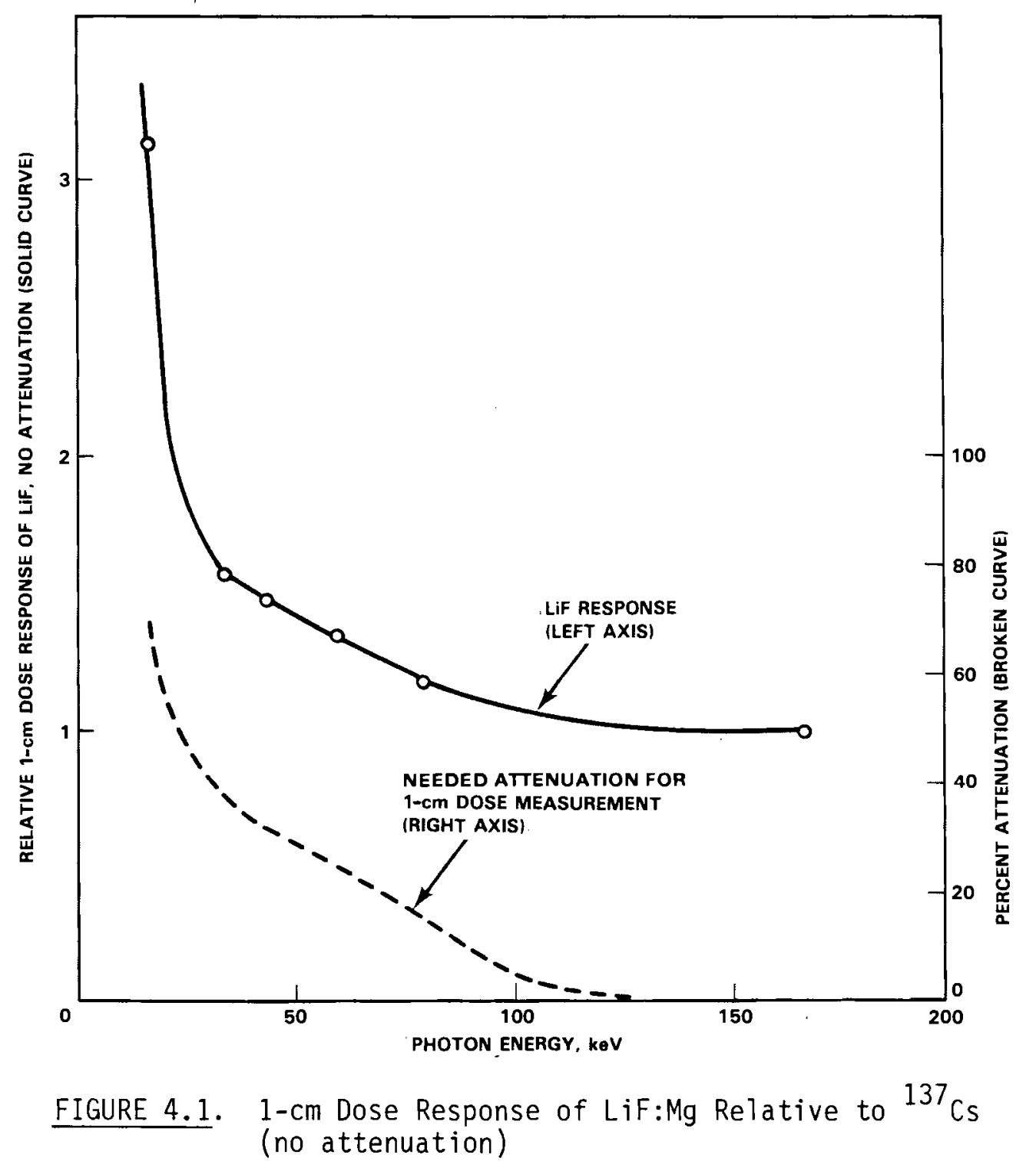


irradiated without security credentials to K-fluorescent and heavily filtered $x$-ray techniques. The $1-\mathrm{cm}$ dose response is defined as the ratio of $T L$ signal for a 1 -rem $x$-ray dose to $T L$ signal for $1-$ rem ${ }^{137} \mathrm{Cs}$ at $1 \mathrm{~cm}$. Delivered doses in tissue are calculated from exposure in-air using the conversion factors in ANSI N13.11 (ANSI 1982).

The response relative to ${ }^{137} \mathrm{Cs}$ is high by a factor of three at $16 \mathrm{keV}$, decreasing as photon energy increases. To produce a uniform deep dose response at all energies, the attenuation of the dosimeter holder must compensate for the high response of LiF at low energies. The necessary attenuation is indicated by a broken curve.

A material with a fairly high atomic number is needed to provide attenuation above $34 \mathrm{keV}$. The attenuation from $400-\mathrm{mg} / \mathrm{cm}^{2} \mathrm{tin}$, for example, is given in Figure 4.2. If one fourth of the $400-\mathrm{mg} / \mathrm{cm}^{2}$ tin attenuation is utilized, the desired attenuation for $1-\mathrm{cm}$ dose is matched above $34 \mathrm{keV}$. Physically,

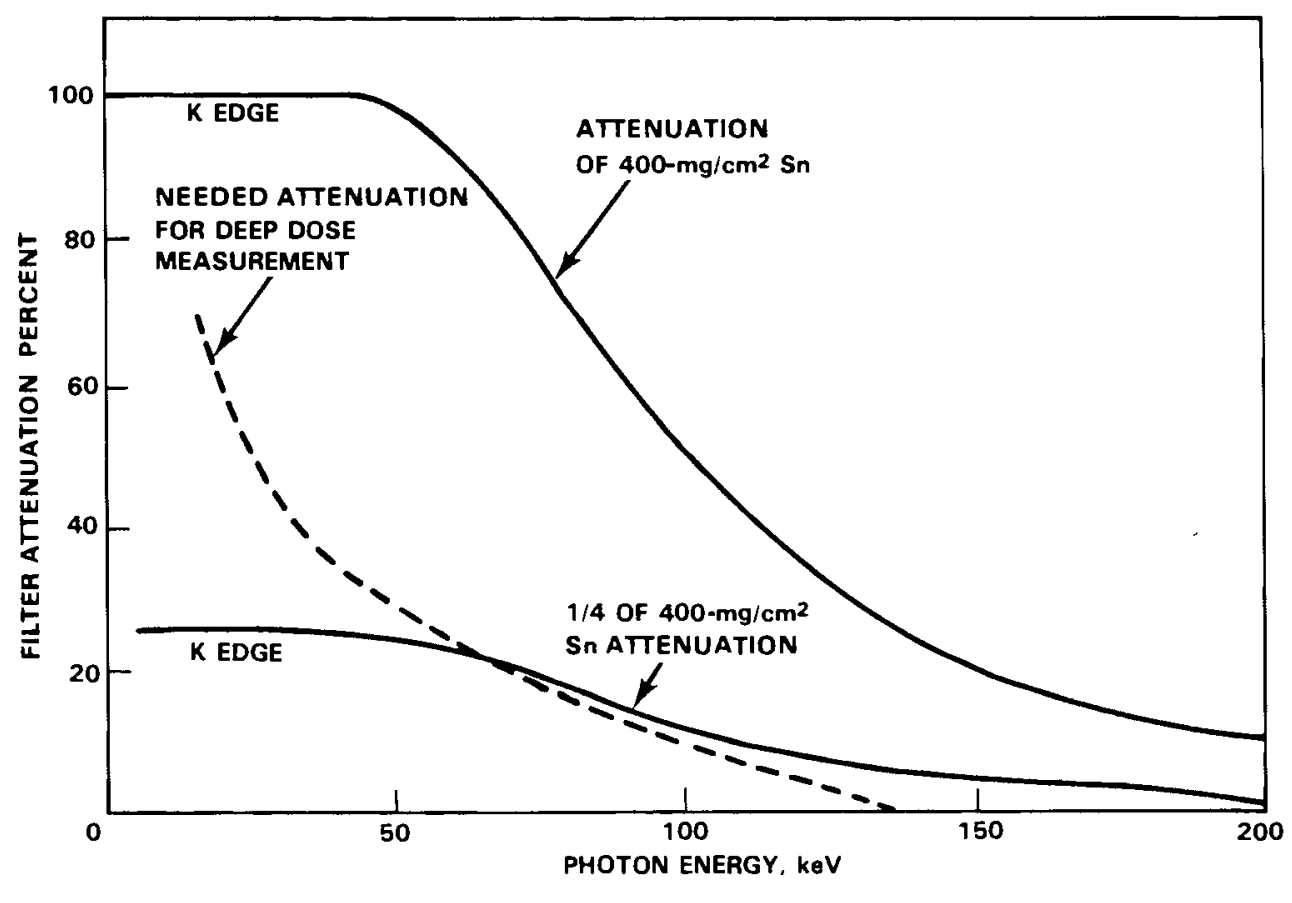

FIGURE 4.2. Attenuation of the Tin Filter 
this is obtained by combining one fourth of the signal from the filtered TLD with three-fourths of the open window signal. Use of smaller tin thicknesses is not beneficial since the attenuation remains high at low energies, decreasing rapidly at energies above $50 \mathrm{keV}$.

Additional attenuation is required below $34 \mathrm{keV}$ to obtain a more uniform response. Filter materials with low atomic numbers provide the necessary attenuation at lower energies without impairing the TLD response above $34 \mathrm{keV}$. The attenuation needed after subtracting $1 / 4$ of the tin attenuation from the desired attenuation is shown in Figure 4.3 . Curves for $500-\mathrm{mg} / \mathrm{cm}^{1}, 180-\mathrm{mg} / \mathrm{cm}^{2}$, and $80-\mathrm{mg} / \mathrm{cm}^{2}$ aluminum are included for comparison. When $3 / 4$ of the attenuation from $80-\mathrm{mg} / \mathrm{cm}^{2}$ aluminum is added to $1 / 4$ of the attenuation from $400 \mathrm{mg} / \mathrm{cm}^{2}$ tin, the needed attenuation for the $1-\mathrm{cm}$ deep dose is obtained (Figure 4.4). In a dosimeter, the $1-\mathrm{cm}$ dose would be calculated based on $1 / 4$ of the tinfiltered TLD signal and $3 / 4$ of the aluminum-filtered TLD signal.

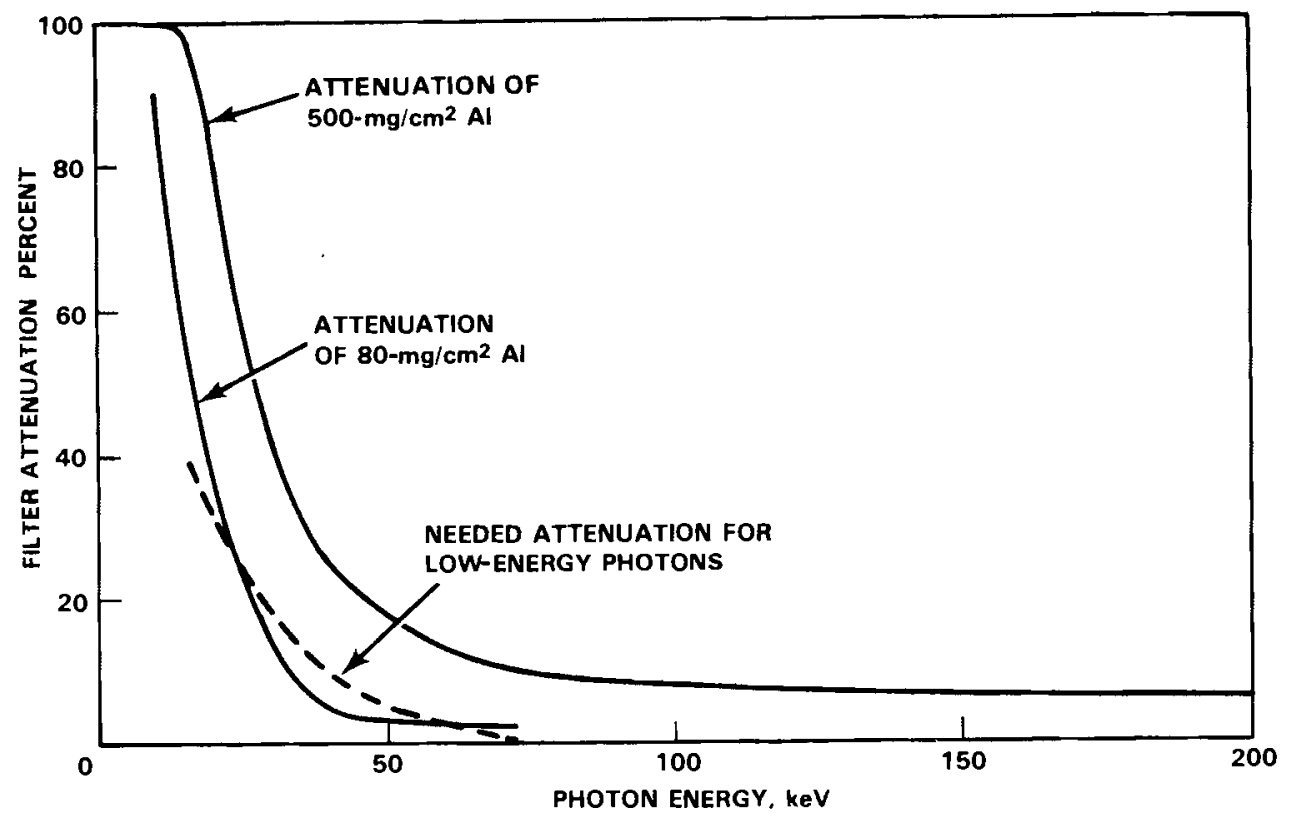

FIGURE 4.3. Necessary Attenuation of the Aluminum Filter 


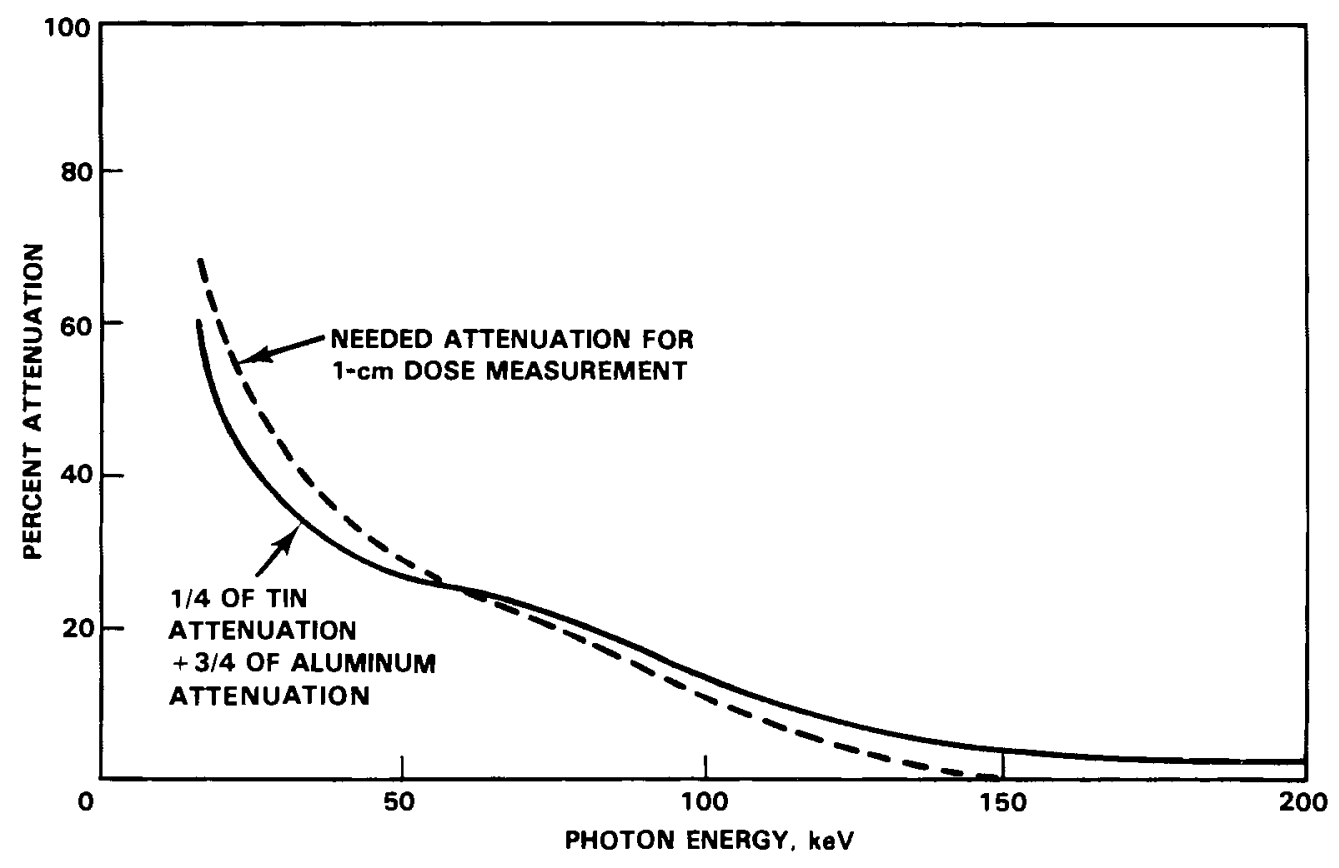

FIGURE 4.4. Attenuation for 1-cm Dose Measurement

The tin and aluminum design was selected for material availability and ease of fabrication. Other combinations of materials with high and low atomic numbers are useful; however, most of the other materials considered were more expensive. The available tin and aluminum thicknesses used for fabrication of the prototype dosimeter differed slightly from the specified values. The aluminum and tin filters in the fabricated design were $75-\mathrm{mg} / \mathrm{cm}^{2}$ and $408-\mathrm{mg} / \mathrm{cm}^{2}$, respectively.

\section{Photon Shallow Dose Response}

The procedure for designing a dosimeter to measure shallow dose is similar to that used in the deep dose design. Satisfactory attenuation combinations were obtained with the design proposed for deep dose measurement. Subtraction of chip response is necessary. The approach is demonstrated in Figures 4.5 and 4.6 . 


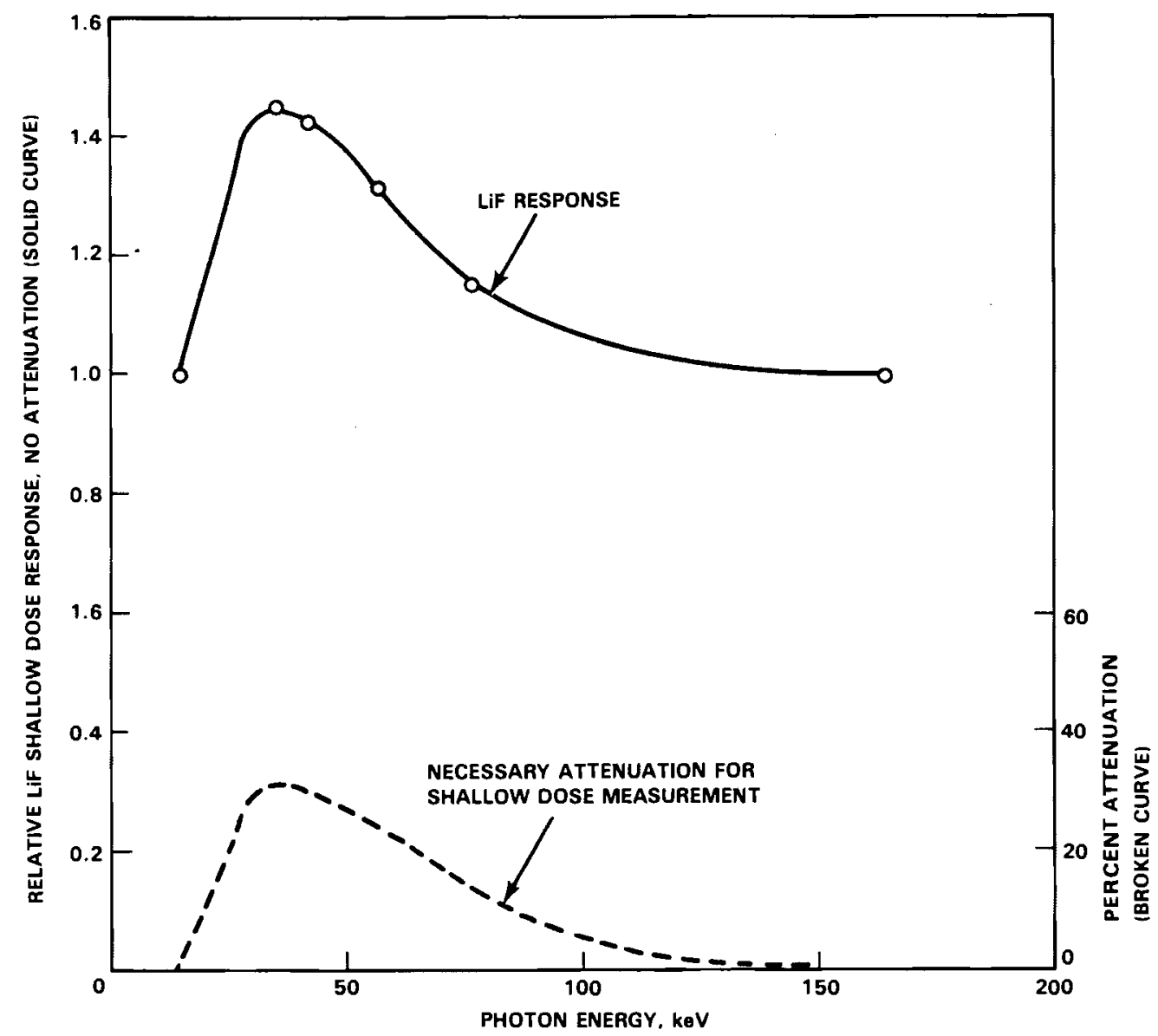

FIGURE 4.5. Shallow $(0.007-\mathrm{cm})$ Dose Response, Relative to ${ }^{137} \mathrm{Cs}$, of Unfiltered TLD-700

\section{BETA DOSIMETER CONCEPTS}

The shallow dose from $x$ rays and betas should be accurately measured. This is especially difficult for betas when conventional TLDs, which have a density thickness much greater than $7-\mathrm{mg} / \mathrm{cm}^{2}$, are used to measure dose at $7-\mathrm{mg} / \mathrm{cm}^{2}$ in tissue. Standard TLD-700s (35 mil) have a density thickness of $235 \mathrm{mg} / \mathrm{cm}^{2}$. Thin TLDs (15 $\mathrm{mil}$ ) represent an improvement in beta dose measurement, but are also inadequate $\left(100-\mathrm{mg} / \mathrm{cm}^{2}\right)$. Both types of phosphor require a beta energy correction based on attenuation for the dosimeter positions. The prototype dosimeter utilizes a standard 35-mil TLD-700 in the open window position. Beta algorithms are developed for both thin and thick TLDs in Section 5.0 . 


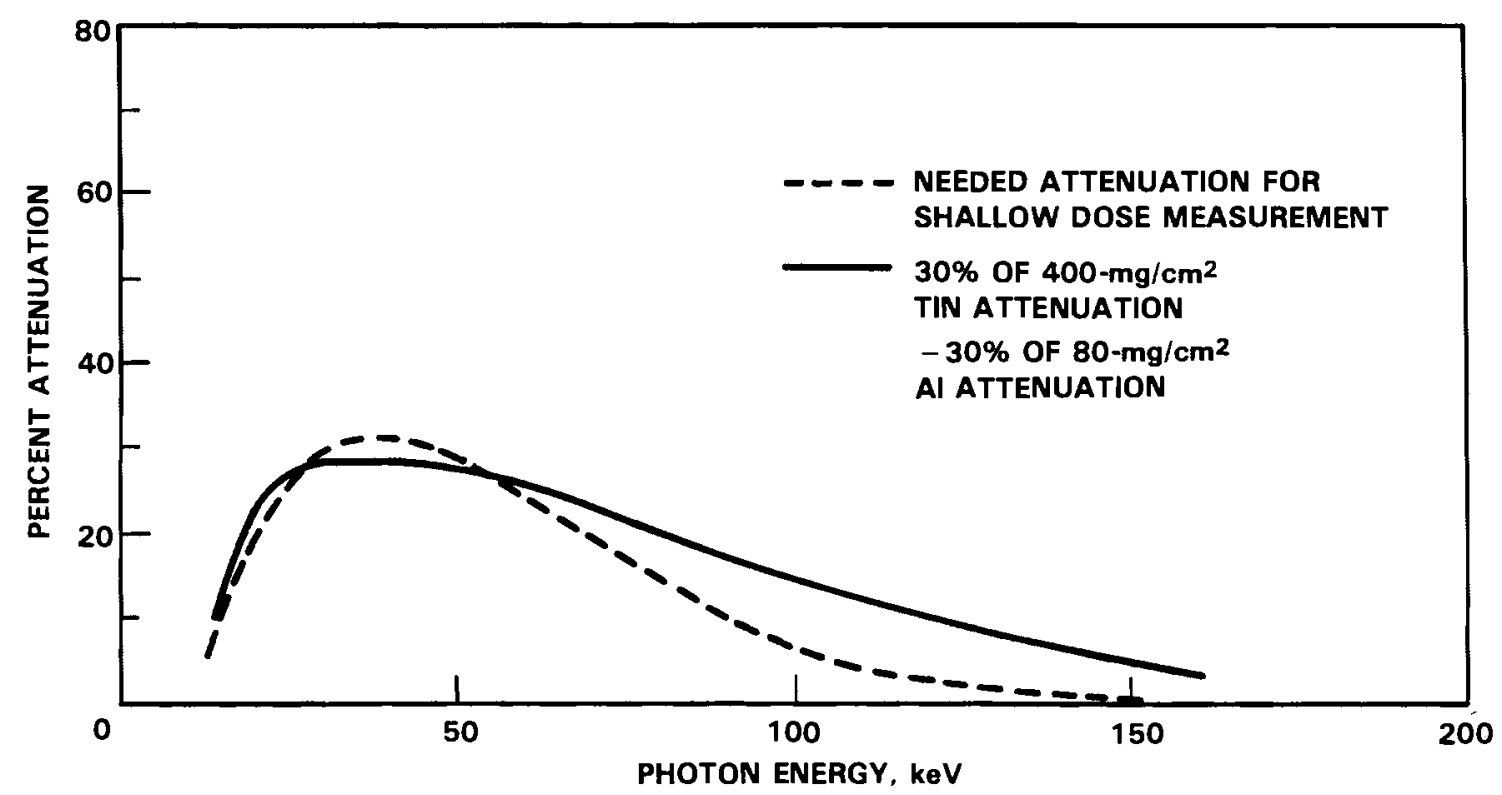

FIGURE 4.6. Design of a Dosimeter to Measure Shallow Dose From Photons

The prototype design utilizes two LiF elements covered by $80-\mathrm{mg} / \mathrm{cm}^{2}$ aluminum to distinguish between "high-energy" betas $\left({ }^{90} \mathrm{Sr} / \mathrm{Y}\right)$ and $\mathrm{x}$ rays. A $3300-\mathrm{mg} / \mathrm{cm}^{2}$ polyethylene filter added to one of the aluminum filters elements attenuates betas with energies below $0.8 \mathrm{MeV}$. $X$ rays with extremely low energies are also attenuated. The calculated attenuations for $15-\mathrm{keV}$ and $10-\mathrm{keV}$ photons are $20 \%$ and $50 \%$, respectively. At $40 \mathrm{keV}$, the effect is negligible. At $16 \mathrm{keV}$, transmission through the plastic is sufficient to allow discrimination between low-energy photons and betas. The open window chip can be used to evaluate beta dose with energy corrections applied for response to low-energy betas. The prototypes did not include the existing security credential, since this seriously impairs the ability to measure low-energy betas. 


\subsection{ALGORITHM DEVELOPMENT}

The dosimeter design presented in Section 4.0 provides a starting point for algorithm development. The designs were based on calculated mass attenuation coefficients of the aluminum and tin filters. Effects of scatter in holder materials and attenuation by plastic in the holder were not considered in the calculations. Algorithms used for a given design should be developed from actual laboratory data.

Optimum algorithms for photon and beta radiation were developed based on exposures of the test dosimeters to $K$-fluorescent $x$-ray energies of $14,34,43$, and $58 \mathrm{keV}$, heavily filtered x-ray technique HFI (effective energy $167 \mathrm{keV}$ ), ${ }^{137} \mathrm{Cs}$, a disc geometry ${ }^{90} \mathrm{Sr} / \mathrm{Y}$ source, a spherical ${ }^{90} \mathrm{Sr} / \mathrm{Y}$ source, ${ }^{85} \mathrm{Kr}$ and ${ }^{204} \mathrm{Tl}$. Al1 beta source and x-ray irradiations were performed on a phantom. Cesium exposures were conducted in air, with a $10 \%$ backscatter correction applied to the TLD signal. TLD readings were corrected for individual chip sensitivities based on screening irradiations to ${ }^{137} \mathrm{Cs}$.

TLD response data are summarized in Tables 5.1 through 5.3. For photon irradiations, the exposure response is equal to the TL response per unit exposure to $x$ rays divided by the $T L$ response per unit exposure to ${ }^{137} \mathrm{Cs}$. The shallow and deep dose responses were calculated as follows:

$$
D R(E)=E R(E) \frac{C_{x}\left({ }^{137} C_{S}\right)}{C_{x}(E)}
$$

where $D R(E)$ is the shallow or deep dose response relative to ${ }^{137} C S$ at energy $E$, $E R(E)$ is the exposure response relative to ${ }^{137} C_{s}$, and the $C_{x}$ values are the exposure-to-dose-equivalent conversion factors given in ANSI N13.11 (ANSI 1982). For the HFI technique, no conversion factors are given in ANSI N13.11; $C_{x}$ values were obtained from PNL-3219 (Yoder et al. 1979).

A least squares fit was used to minimize bias errors at each energy. Photon and beta algorithms were developed separately. For the photon dose, an 

TABLE 5.1. TLD Response for the LiFaMultielement Dosimeter
(background subtracted)

\begin{tabular}{|c|c|c|c|c|}
\hline Source & Position 1 & Position 2 & Position 3 & Position 4 \\
\hline${ }^{137} \mathrm{Cs}$ & $1540 \pm 10$ & $1377 \pm 6$ & $1577 \pm 1$ & $1419 \pm 7$ \\
\hline $16 \mathrm{keV}$ & $1543 \pm 22$ & $778 \pm 3$ & $24 \pm 4$ & $769 \pm 8$ \\
\hline $34 \mathrm{keV}$ & $2556 \pm 37$ & $2248 \pm 20$ & $297 \pm 9$ & $2351 \pm 45$ \\
\hline $43 \mathrm{keV}$ & $2820 \pm 26$ & $2473 \pm 32$ & $421 \pm 12$ & $2687 \pm 24$ \\
\hline $58 \mathrm{keV}$ & $2908 \pm 104$ & $1704 \pm 66$ & $762 \pm 14$ & $2814 \pm 42$ \\
\hline HFI (167 keV) & $1850 \pm 20$ & $1764 \pm 25$ & $1629 \pm 18$ & $1811 \pm 22$ \\
\hline${ }^{90}$ Sr PTB & $1326 \pm 13$ & $745 \pm 7$ & $86 \pm 5$ & $134 \pm 3$ \\
\hline${ }^{90}$ Sr sphere & $1073 \pm 14$ & $528 \pm 15$ & $63 \pm 4$ & $89 \pm 4$ \\
\hline${ }^{204} \mathrm{~T} 1$ & $440 \pm 11$ & $4 \pm 1$ & $4 \pm 2$ & $2 \pm 3$ \\
\hline
\end{tabular}

(a) Dosimegters were exposed to $1 \mathrm{R}$ for $16 \mathrm{keV}, 34 \mathrm{keV}$ and $43 \mathrm{keV}$. Results for ${ }^{13}$ Cs, $59 \mathrm{keV}$ and HFI $x$ rays are based on exposures to $500 \mathrm{mR}$, normalized to 1 R. Cesium irradiations were performed in air, with a $10 \%$ correction applied to simulate backscatter from a phantom. All other irradiations were performed on a phantom. Beta irradiations were 1 rad.

TABLE 5.2. TLD Shallow Dose Response Relative to ${ }^{137} \mathrm{Cs}$

\begin{tabular}{|c|c|c|c|c|}
\hline Source & Position 1 & Position 2 & Position 3 & Position 4 \\
\hline${ }^{137} \mathrm{Cs}$ & 1.00 & 1.00 & 1.00 & 1.00 \\
\hline $16 \mathrm{keV}$ & 1.13 & 0.64 & 0.02 & 0.61 \\
\hline $34 \mathrm{keV}$ & 1.42 & 1.40 & 0.16 & 1.42 \\
\hline $58 \mathrm{keV}$ & 1.36 & 1.33 & 0.20 & 1.40 \\
\hline HF I & 0.94 & 1.01 & 0.81 & 1.00 \\
\hline${ }^{90}$ Sr PTB & 0.88 & 0.56 & 0.06 & 0.10 \\
\hline${ }^{90}$ Sr sphere & 0.72 & 0.39 & 0.04 & 0.07 \\
\hline${ }^{204} \mathrm{Tl}$ & 0.29 & 0.003 & 0.00 & 0.00 \\
\hline${ }^{85} \mathrm{Kr}(\mathrm{a})$ & 0.27 & - & - & - \\
\hline
\end{tabular}

(a) The ${ }^{85} \mathrm{Kr}$ response is based on data for Hanford dosimeters irradiated
without security credentials. 
TABLE 5.3. Deep Dose Response Relative to ${ }^{137} \mathrm{CS}$

\begin{tabular}{|c|c|c|c|}
\hline Source & Position 2 & Position 3 & Position 4 \\
\hline${ }^{137} \mathrm{Cs}$ & 1.00 & 1.00 & 1.00 \\
\hline $14 \mathrm{keV}$ & 1.76 & 0.05 & 1.69 \\
\hline $34 \mathrm{keV}$ & 1.53 & 0.18 & 1.55 \\
\hline $58 \mathrm{keV}$ & 1.28 & 0.34 & 1.39 \\
\hline HF I & 1.01 & 0.81 & 1.00 \\
\hline
\end{tabular}

equation of the form

$$
\text { Dose }=\sum_{i=1}^{N} C_{i} R_{i}
$$

was assumed, where $N$ is the number of dosimeter positions used, $R_{i}$ is the shallow or deep dose response of position i relative to a 1-rem on-phantom exposure of ${ }^{137} \mathrm{Cs}$, and $C_{j}$ is the fraction of position $i$ signal used in calculating dose. The sum of the coefficients is set equal to one, so that the response to ${ }^{137} \mathrm{Cs}$ is always unity. The least squares calculation is described fully in Appendix A. Optimum values for each coefficient were calculated based on the TLD response data.

The photon deep dose calculation is based upon the responses of position 3 $\left(408-\mathrm{mg} / \mathrm{cm}^{2} \mathrm{Sn}+57-\mathrm{mg} / \mathrm{cm}^{2} \mathrm{plastic}\right)$ and position $4\left(75-\mathrm{mg} / \mathrm{cm}^{2}\right.$ aluminum + $368-\mathrm{mg} / \mathrm{cm}^{2}$ plastic). The filtrations over both positions eliminate most of the false depth dose reading from ${ }^{90} \mathrm{Sr} / \mathrm{Y}$, a common problem with beta-gamma dosimeters. The equation obtained from the least squares fit is similar to the algorithm derived in Section 4.0 .

$$
\text { Deep dose }(1 \mathrm{~cm})=0.385 R_{3}+0.615 R_{4}
$$

The predicted dosimeter response, given in Table 5.4 , is based on the data for the least squares fit. The dosimeter response is expected to be within $7 \%$ of the delivered photon dose, neglecting calibration uncertainties and TLD variability. The performance was evaluated through exposure to filtered $x$-ray techniques, discussed in Section 6.0. 
TABLE 5.4. Predicted Deep Dose Response of the LiF Multielement Dosimeter

\begin{tabular}{lcc}
\multicolumn{1}{c}{ Source } & $0.385 \mathrm{R}_{3}+0.615 \mathrm{R}_{4}$ & Predicted Bias \\
\cline { 1 - 1 } $16 \mathrm{keV}$ & 1.00 & $6 \%$ \\
$34 \mathrm{keV}$ & 1.021 & $2 \%$ \\
$43 \mathrm{keV}$ & 0.971 & $-3 \%$ \\
$58 \mathrm{keV}$ & 0.99 & $-1 \%$ \\
$\mathrm{HFI}(167 \mathrm{keV})$ & 0.93 & $-7 \%$ \\
${ }^{137} \mathrm{Cs}$ & 1.00 & $0 \%$
\end{tabular}

For shallow dose, two options were considered. Photon shallow dose can be evaluated independently of beta dose, using positions 3 and 4 . A separate beta algorithm performs a beta energy correction after subtracting the photon component. If photon doses are not calculated independently of beta doses, position 1 (open window) can be used. The response to photons is improved by adding position 1, with interpretation of beta-photon mixtures becoming more difficult.

If positions 3 and 4 are used to assess the shallow dose from photons, the optimum chip combination is:

$$
\text { Dose }=0.253 R_{3}+0.747 R_{4}
$$

using TLD signal relative to $1-R{ }^{137} \mathrm{Cs}$. The predicted response is summarized in Table 5.5. Low-energy $x$-ray response is very low. For photons with energies in the 30 to $662 \mathrm{keV}$ range, the bias is $10 \%$ or less. Inclusion of the open window position improves the performance at low energies. The algorithm becomes:

$$
\text { Dose }=1.056 R_{1}+0.298 R_{3}-0.354 R_{4}
$$

$X$-ray response is within $5 \%$ of delivered dose, except for the heavily filtered technique. The predicted response for HFI is $12 \%$ low. 
TABLE 5.5. Predicted Shallow Dose Response of LiF Multielement Dosimeter

\begin{tabular}{|c|c|c|}
\hline $\begin{array}{l}\text { Source } \\
\text { (1-rem exposure) }\end{array}$ & $\begin{array}{c}0.253 R_{3}+0.747 R_{4} \\
(\mathrm{rem})\end{array}$ & $1.056 R_{1}+\frac{0.298 R_{3}}{(r e m)}-0.354 R_{4}$ \\
\hline${ }^{137} \mathrm{Cs}$ & 1.00 & 1.00 \\
\hline $16 \mathrm{keV}$ & 0.46 & 0.98 \\
\hline $34 \mathrm{keV}$ & 1.10 & 1.04 \\
\hline $43 \mathrm{keV}$ & 1.10 & 0.98 \\
\hline $58 \mathrm{keV}$ & 1.08 & 0.88 \\
\hline & 0.95 & 0.88 \\
\hline${ }^{90}$ Sr PTB $(a)$ & 0.09 & 0.75 \\
\hline${ }^{204} 4_{T 1}(\mathrm{a})$ & 0.00 & 0.30 \\
\hline
\end{tabular}

(a) For reference only (beta doses are calculated separately).

Beta algorithms were developed for four sources. The PTB ${ }^{90}$ Sr disc source, manufactured by Buchner $\mathrm{GMbH}$, has an $\mathrm{Ag}$ filter of $50 \mathrm{mg} / \mathrm{cm}^{2}$. The spherical ${ }^{90} \mathrm{Sr} / \mathrm{Y}$ source has a filtration of $100 \mathrm{mg} / \mathrm{cm}^{2}$. The effective energy of the spherical source is lower than that of the disc source due to differences in filtration and scatter conditions. Given identical delivered shallow doses, the response of a bare TLD-700 (0.25-mil mylar filtration) is approximately 20\% lower for the sphere. Thallium-204 has a maximum energy of $0.76 \mathrm{MeV}$. The maximum beta energy of ${ }^{85} \mathrm{Kr}$ is 0.69 .

A conceptualized drawing of the beta dosimeter is shown in Figure 5.1. For photons above $30 \mathrm{keV}$, the attenuation of the added $311-\mathrm{mg} / \mathrm{cm}^{2}$ polyethylene over position 4 is insignificant, and the difference in signal between positions 2 and 4 is due entirely to betas. If the photon component is subtracted from position 1, the dosimeter can be used as a beta spectrometer.

The open window signal is used to assess beta dose after subtracting the photon signal of position 4. A response correction is obtained from the TLD readings of positions 1,2 , and 4 . The correction is of the form:

$$
C_{\text {beta }}(E)=A\left[1-\left(\frac{R_{2}-R_{4}}{R_{1}-R_{4}}\right)^{B}\right]
$$




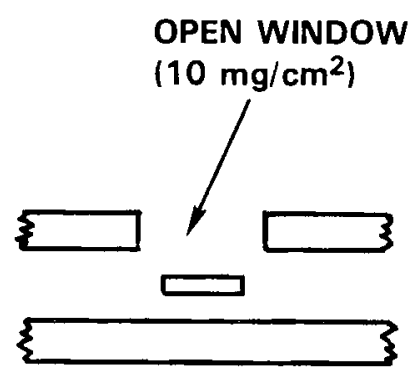

POSITION 1 75-mg/ $\mathrm{cm}^{2}$ ALUMINUM

$+93-\mathrm{mg} / \mathrm{cm}^{2}$ PLASTIC

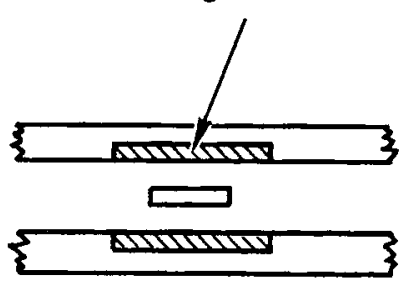

POSITION 2

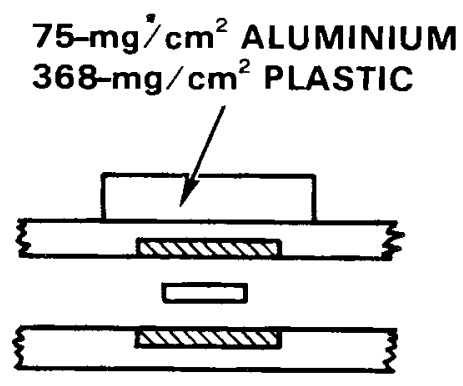

POSITION 4 (PHOTON SUBTRACTION)

FIGURE 5.1. Conceptualized Beta Dosimeter

where $R$ is the TLD response normalized to $1-$ rem ${ }^{137} \mathrm{Cs}$, and $A$ and $B$ are constants. Betas with very low energies are attenuated by the position 2 filter, and the difference $R_{2}-R_{4}$ is zero. At low energies, the beta response correction is equal to the constant $A$. As beta energy increases, the ratio of $\left(R_{1}-\right.$ $R_{4}$ ) to $\left(R_{2}-R_{4}\right)$ increases, and the response correction becomes smaller. The equation for calculating beta dose, then, is:

$$
\text { Beta Dose }=A\left[1-\left(\frac{R_{2}-R_{4}}{R_{1}-R_{4}}\right)^{B}\right]\left(R_{1}-R_{4}\right)
$$

Values of $\left(R_{1}-R_{4}\right)$ and $\left(R_{2}-R_{4}\right)$ are listed in Table 5.6.

The constant $A$ was derived for ${ }^{85} \mathrm{Kr}$. $A$ is equal to the inverse of $\left(R_{1}\right.$ $R_{4}$ ), or 3.70 . The constant $B$ was obtained by substituting TLD response values for the PTB ${ }^{90} \mathrm{Sr}$ source and setting the beta dose equal to 1 rad. A value of 0.81 was obtained. When delivered doses are calculated using the TLD responses for the four doses, the bias in calculating dose from the ${ }^{90} \mathrm{Sr}$ sphere and ${ }^{204} \mathrm{TI}$ source is $5 \%$ neglecting TLD and calibration variability.

The algorithm development was repeated for thin LiF (15 mil) based on the beta energy response data presented in Section 3.0. Data for ${ }^{85} \mathrm{Kr}$ and the ${ }^{90} \mathrm{Sr} / \mathrm{Y}$ sphere were used to develop the equation. The TLD response relative to 1 -rem ${ }^{137}$ Cs is listed in Table 5.7, along with the algorithms developed for thin LiF. The $x$-ray algorithms are not expected to change significantly if thin LiF is substituted in the open window position. 
TABLE 5.7.
Beta Dosimetry Using Thin $13 j \mathrm{~F}$
TLD Response Relative to ${ }^{2}$ S

\begin{tabular}{|c|c|c|c|}
\hline Source & $\mathrm{R}_{1}{ }^{(\mathrm{a})}$ & $\mathrm{R}_{2}$ & $\mathrm{R}_{4}$ \\
\hline${ }^{147} \mathrm{Pm}$ & 0.02 & 0.00 & 0.00 \\
\hline${ }^{85} \mathrm{Kr}$ & 0.38 & 0.002 & 0.002 \\
\hline${ }^{90} \mathrm{Sr}$ sphere & 0.95 & 0.39 & 0.065 \\
\hline
\end{tabular}

(a) 15-mil-thick chip used in position 1. Sample beta algorithm for thin LiF in open window.

$$
\begin{aligned}
\text { Dose } & =A\left[1-\left(\frac{R_{2}-R_{4}}{R_{1}-R_{4}}\right)^{B}\right]\left(R_{1}-R_{4}\right) \\
A & =2.63 \text { (based on }{ }^{85} K r \text { response) } \\
B & =0.56 \text { (based on }{ }^{90} \text { Sr response) }
\end{aligned}
$$

\begin{tabular}{|c|c|c|c|}
\hline Source & $\mathrm{R}_{2} / \mathrm{R}_{1}$ & $\mathrm{R}_{4} / \mathrm{R}_{2}$ & $\mathrm{R}_{3} / \mathrm{R}_{4}$ \\
\hline${ }^{137} \mathrm{Cs}$ & 1.00 & 1.00 & 1.00 \\
\hline $16 \mathrm{keV}$ & 0.57 & 0.95 & 0.03 \\
\hline $34 \mathrm{keV}$ & 0.98 & 1.01 & 0.11 \\
\hline $43 \mathrm{keV}$ & 0.98 & 1.07 & 0.14 \\
\hline $58 \mathrm{keV}$ & 0.98 & 1.08 & 0.24 \\
\hline 90 Sr PTB & 0.64 & 0.18 & - \\
\hline${ }^{204} \mathrm{~T}$ & 0.01 & - & - \\
\hline
\end{tabular}

TABLE 5.8. Chip Response Ratios for the LiF Multielement Dosimeter (for 1-rem-delivered shallow dose) 
TABLE 5.6. Beta Algorithm Development Using Thick TLD-700

(multielement dosimeters irradiated to 1 rad)

\begin{tabular}{|c|c|c|c|c|c|}
\hline Source & $R_{1}-R_{4}$ & $\frac{R_{2}-R_{4}}{R_{1}-R_{4}}$ & 3.70 & {$\left[1-\left(\frac{R_{2}-R_{4}}{R_{2}-R_{4}}\right)^{.81}\right.$} & $\left(R_{1}-R_{4}\right)$ \\
\hline${ }^{90}$ Sr PTB disC & 0.78 & 0.59 & & 1.00 & \\
\hline${ }^{90}$ Sr sphere & 0.66 & 0.50 & & 1.05 & \\
\hline${ }^{204} T 1$ & 0.29 & 0.01 & & 1.05 & \\
\hline${ }^{85} \mathrm{Kr}$ & 0.27 & 0.00 & & 1.00 & \\
\hline
\end{tabular}

Constraints are necessary to avoid false beta signals from low-energy $x$ rays. At $16 \mathrm{keV}, R_{1}=1.13, R_{2}=0.64$, and $R_{4}=0.61$ for a delivered shallow dose of 1 rem. This yields a beta response of $1.73 \mathrm{rem}$. A $16-\mathrm{keV} \times$ ray can be distinguished from a high-energy beta and from other photon energies by comparing the ratios of $R_{2}$ to $R_{4}, R_{1}$ to $R_{2}$, and $R_{3}$ to $R_{4}$. These are summarized in Table 5.8. From these ratios, a set of conditions can be selected to identify an irradiation as primarily low-energy photon. For low-energy photons, an algorithm that correctly determines dose from all photon energies is used. Beta dose will be underestimated. If the conditions for low-energy photons are not met, the primary algorithm calculates beta and photon dose independently. The algorithms are summarized in Table 5.9.

Conditions for the algorithm were selected to allow maximum accuracy in the dose calculation. The error from calculating low-energy photon dose in the beta algorithm was considerably larger than the error from calculating highenergy beta dose in the low energy photon algorithm. Therefore, the photon shallow dose calculation is used if any x-ray energy below $58 \mathrm{keV}$ is indicated. For thin LiF, appropriate substitutions to the beta dose algorithms are made. 
TABLE 5.9. Beta Photon Shallow Dose Algorithms

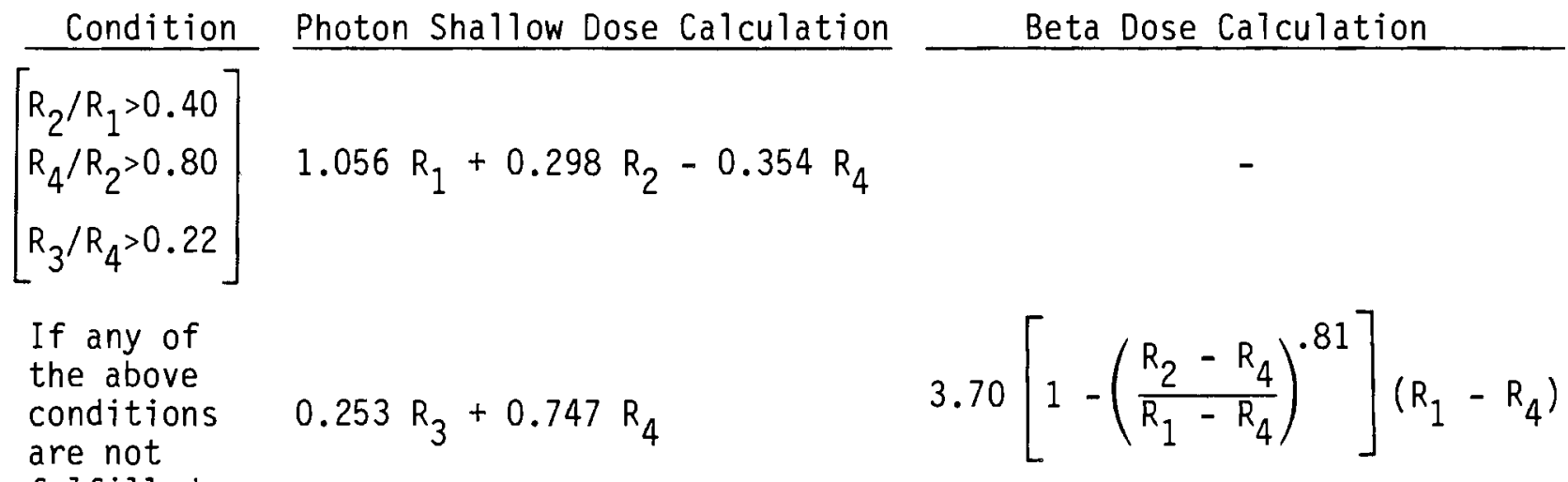




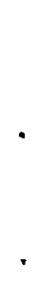




\subsection{LABORATORY EVALUATION}

Evaluation of the phosphor and dosimeter prototypes discussed in earlier sections was conducted with respect to 1) their technical enhancement of beta-gamma personnel dosimetry and 2) their relative impact on the existing system. For comparison, several of the enhanced calibration and algorithm techniques were applied to the existing Hanford dosimeter. The evaluation is presented in a progressive format giving the technical merits of identified changes and program modifications necessary to implement these changes.

\section{CURRENT DOSIMETER SYSTEM}

The present dosimeter system has been examined in detail during the FY-1980 and FY-1981 studies (Fix 1981; Fix 1982). This system involves a 4-chip dosimeter and two automatic readers. Penetrating, nonpenetrating, slow neutron, and fast neutron doses are determined with this system. Chip positions 1 and 2 are used to calculate nonpenetrating and penetrating doses. Chip positions 3 and 4 along with chip position 2 are used to calculate neutron doses. A 5-chip dosimeter has also been used at Hanford. This dosimeter is identical to the 4-chip dosimeter except for an additional TLD-700 chip whose filtration is identical with chip position 3 and very similar to chip position 4. Presently, 4-chip dosimeters are being phased out in preference for the 5-chip dosimeters. For the 5-chip dosimeter, chip positions 1 and 2 are used to calculate nonpenetrating and penetrating doses whereas chip positions 3,4 , and 5 are used to calculate neutron doses.

Current Dosimeter

The beta and photon response characteristics of the existing dosimeter system were analyzed by Cummings et al. in Study 3 of the FY-1980 program and Roberson et al. in Study 2 of the FY-1981 program (Fix 1981; Fix 1982). Pertinent aspects of this information are repeated here to allow comparison with the response following dosimeter modification in the following sections. It is important to note that the dosimeter response is a combination of several factors including its design, calibration procedures, and dose algorithm. 
Figure 6.1 shows the reported skin dose (nonpenetrating plus penetrating) response of the existing dosimeter with and without the security credential to selected beta button sources mounted on wood holders and stored in 318 building. This response is primarily dependent on the calibration source used which is currently aged natural uranium discs adjusted by a factor of 2 to make this calibration equivalent to a ${ }^{90} \mathrm{Sr} / \mathrm{Y}$ source calibration in the 3745 building (Study 2, Fix 1982). No dosimeter or chip (see Table 3.3) response was observed to a ${ }^{147} \mathrm{Pm}$ source $\left(\mathrm{E}_{\max }=0.225 \mathrm{MeV}\right.$ ). This is attributable to the low energy of these beta particles and the presence of sufficient filtration from the air and material overlaying the chip to eliminate these beta particles.

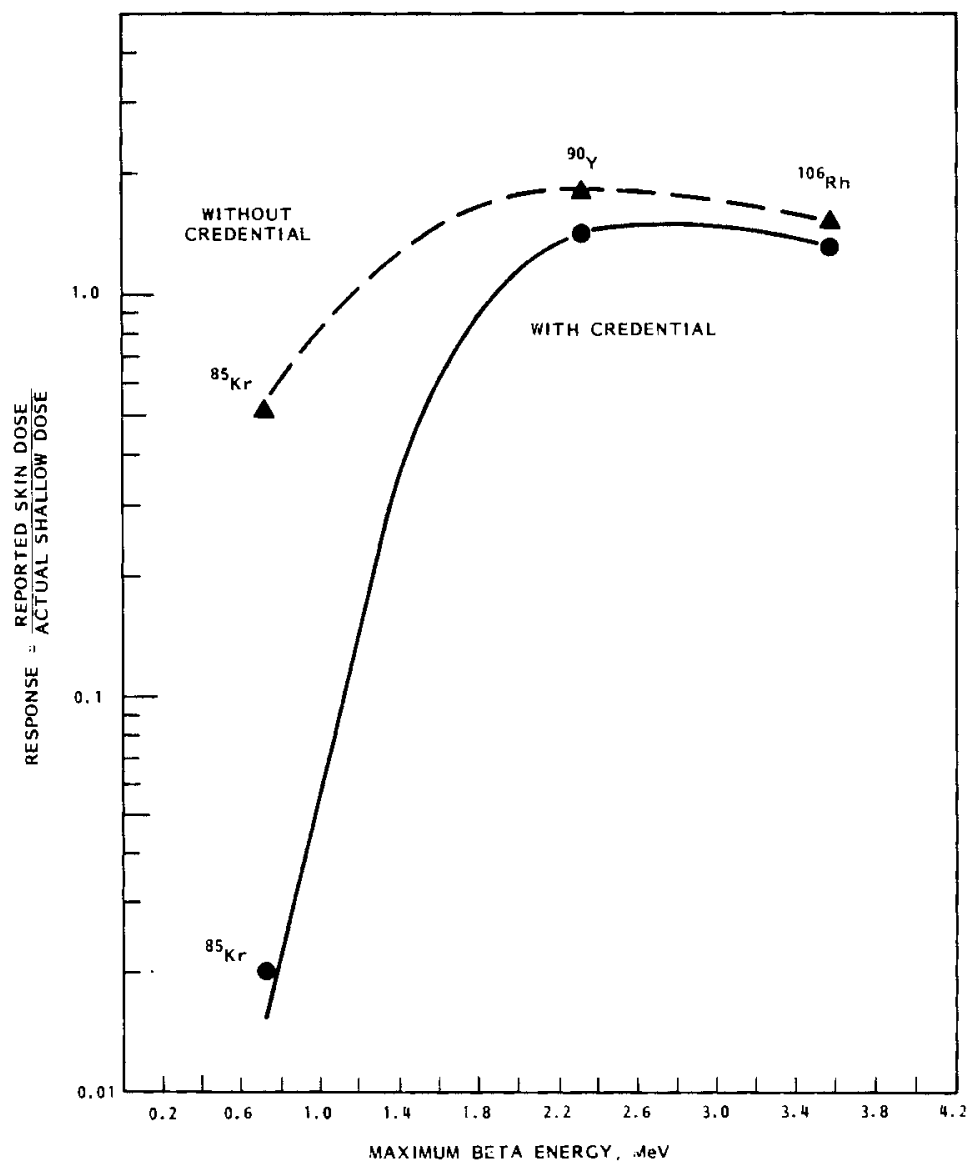

FIGURE 6.1. Comparison of Delivered Shallow and Reported Skin Dose for the Hanford Dosimeter with and without the Security Credential for Selected Nuclides 
The current dosimeter shallow dose response to K-fluorescent photons is shown in Figure 6.2 as the small circles. The overresponse to low-energy photons is attributable to the overresponse of TLD-700 chips relative to the chip response from ${ }^{137}$ Cs gamma radiation. The associated deep dose response is shown in Figure 6.3; this response is similar to the shallow dose response.

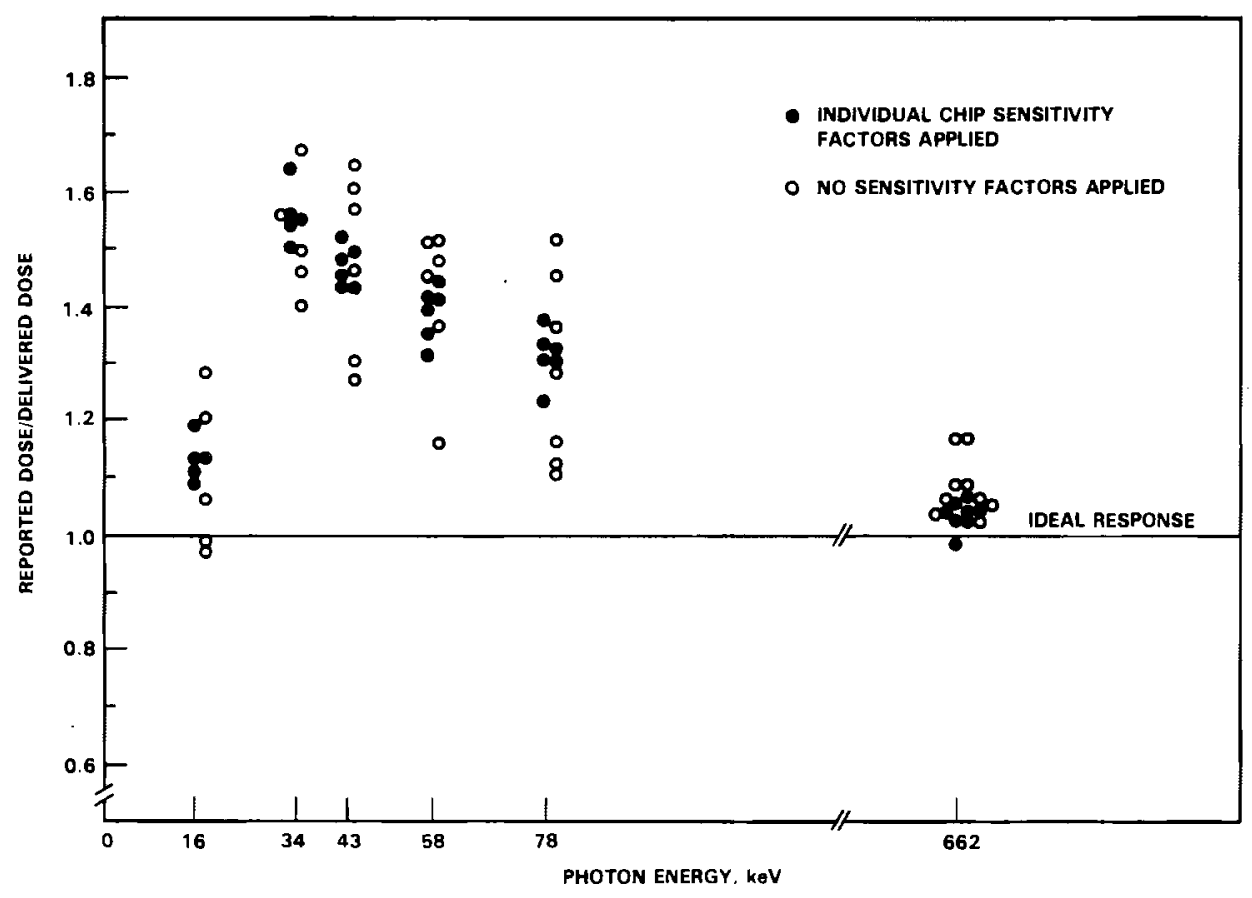

FIGURE 6.2. Comparison of Delivered and Calculated Shallow Dose Using Existing Algorithm for Original Chip Signals and Revised Chip Signals Based on Individual Chip Sensitivity Factors 


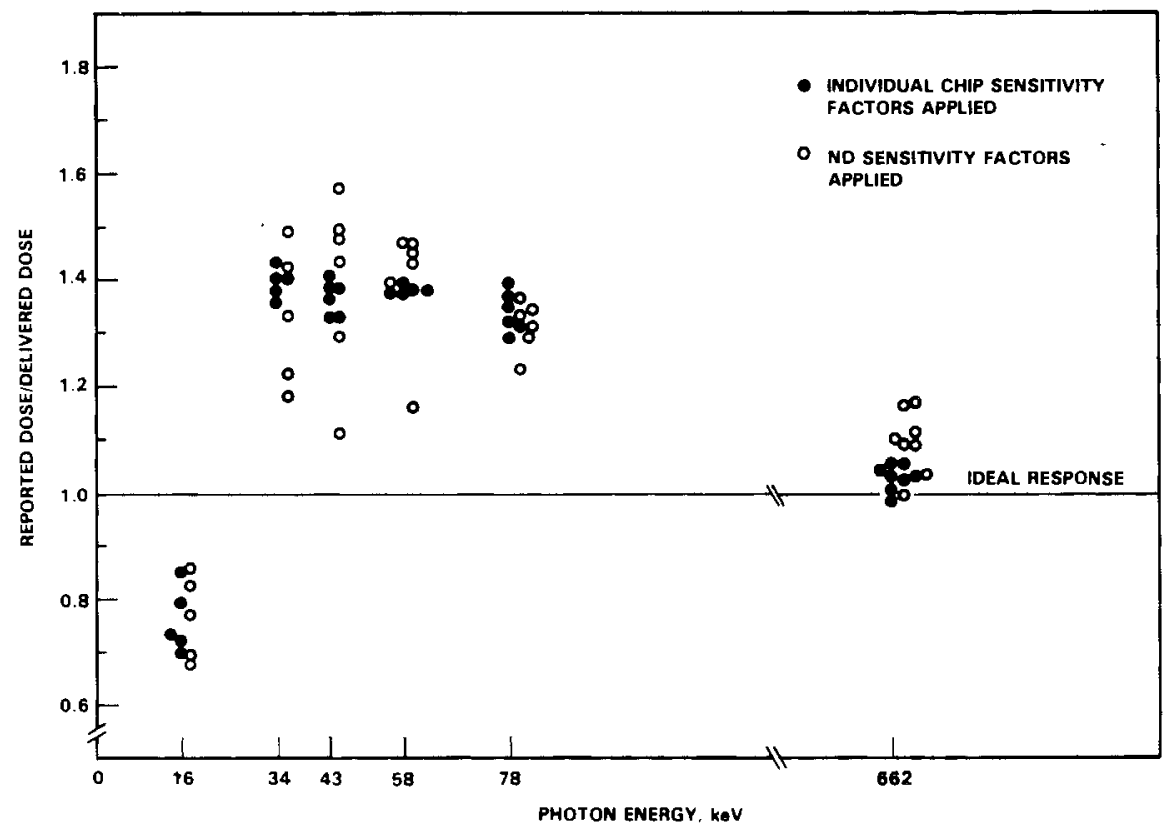

FIGURE 6.3. Comparison of Delivered and Calculated Deep Dose Using Existing Algorithm and Original Chip Signals and Revised Chip Signals Based on Individual Chip Sensitivity Factors

Individual Phosphor Sensitivity Factors

An improvement in the existing system involving better precision can be realized by uniquely labeling each dosimeter card and establishing relative sensitivity factors for each phosphor through a series of reproducible exposures. Sixty routine Hanford dosimeters were exposed four times each to $200 \mathrm{mR}$ of ${ }^{137} \mathrm{Cs}$ gamma radiation and these data used to establish sensitivity factors for each phosphor. To assess the performance improvement, dosimeter results were compared using routine procedures for the original chip readings and for revised chip readings where the reading of each chip was adjusted for its relative sensitivity. Dosimeters were exposed to several $k$-fluorescent $x$ rays. This information is shown in Figures 6.2 and 6.3 as the dark data points.

The primary improvement from using individual phosphor sensitivity factors is to reduce the variability of chip signals for identical exposures and thus better precision for calculated doses. The bias of the dosimeter results remains relatively unchanged as this must be compensated for by using different calibration information and a different algorithm. 
To implement this change, a means to uniquely label each dosimeter card and automatically read this label during routine processing is needed. This process is similar to the bar code technique currently employed to identify the person to whom the dosimeter card is assigned. For each dosimeter card, sensitivity factors are determined by repeated exposure to ${ }^{137}$ Cs gamma (e.g., $200 \mathrm{mR}$ ) and readout (e.g., four times). The mean chip response would provide the sensitivity factor. The variability of the readings for each chip should be examined to determine an acceptable level of precision before accepting the sensitivity factors for each dosimeter card.

\section{Improved Aigorithm}

Another improvement in the routine system can be accomplished by improving the existing algorithm using techniques described in Section 5 . The dosimeter results for K-fluorescent $x$ rays shown in Figures 6.2 and 6.3 were re-evaluated using an algorithm based on a least squares fit of the dosimeter chip response to several K-fluorescent $x$ rays. The recalculated shallow and deep doses are shown in Figures 6.4 and 6.5 , respectively, for the original chip signals (circles) and the chip signals adjusted for their relative sensitivity (dots). The algorithms used in the calculations are

$$
\begin{aligned}
& D_{S}=1.17 R_{1}-0.47 R_{2}+0.30 R_{5} \\
& D_{D}=0.81 R_{2}+0.19 R_{5}
\end{aligned}
$$

where

$$
\begin{aligned}
D_{S}= & \text { shallow tissue dose }(0.007 \mathrm{~cm}) \\
D_{D}= & \text { deep tissue dose }(1 \mathrm{~cm}) \\
R_{i}= & \text { chip signal for the ith chip normalized } \\
& \text { to } 1 \text { rem of }{ }^{137} \mathrm{CS} \text { where } i=1,2 \text { or } 5 .
\end{aligned}
$$

It is apparent from Figures 6.4 and 6.5 that the bias of the dosimeter results is significantly reduced using the improved algorithms. It is also apparent that the variability of dosimeter results is reduced using the individual chip sensitivity factors. The normalization to ${ }^{137}$ Cs allows the use of a single, reproducible calibration. 


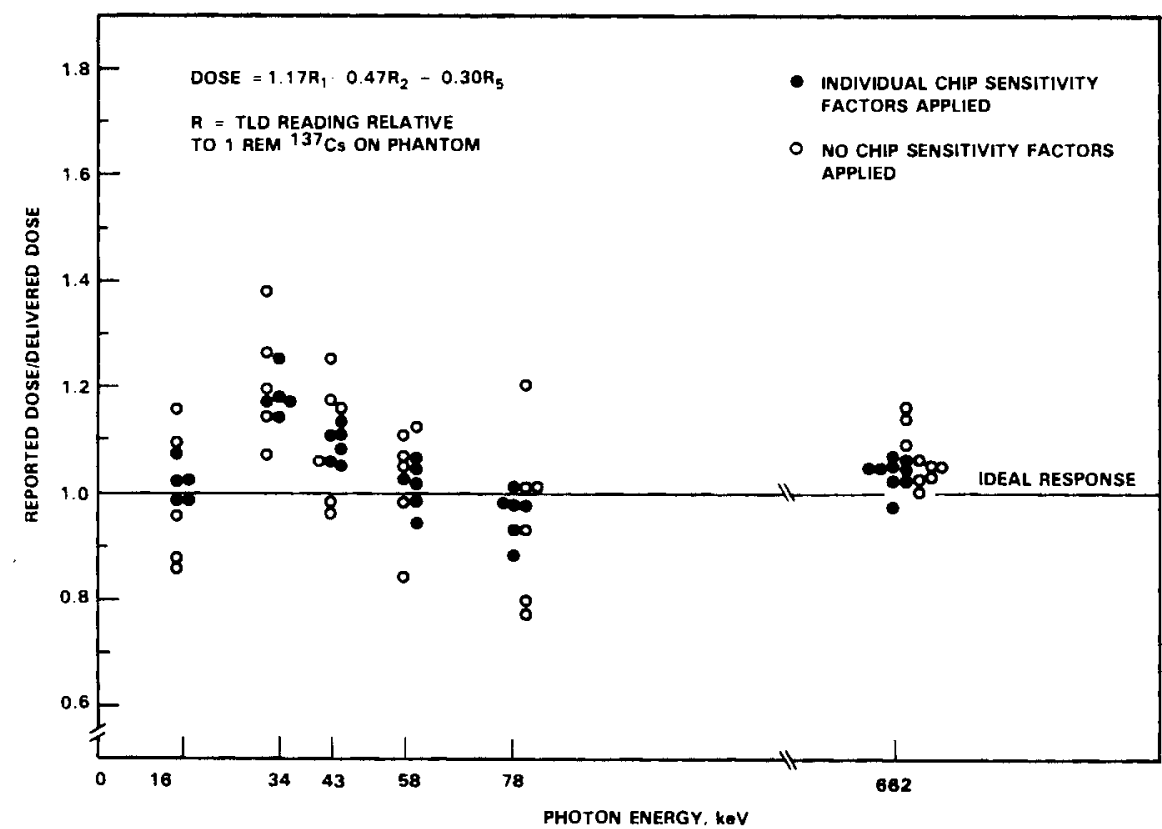

FIGURE 6.4. Comparison of Delivered and Calculated Shallow Dose Using Improved Algorithm for Original and Revised Chip Signals Based on Individual Chip Sensitivity Factors

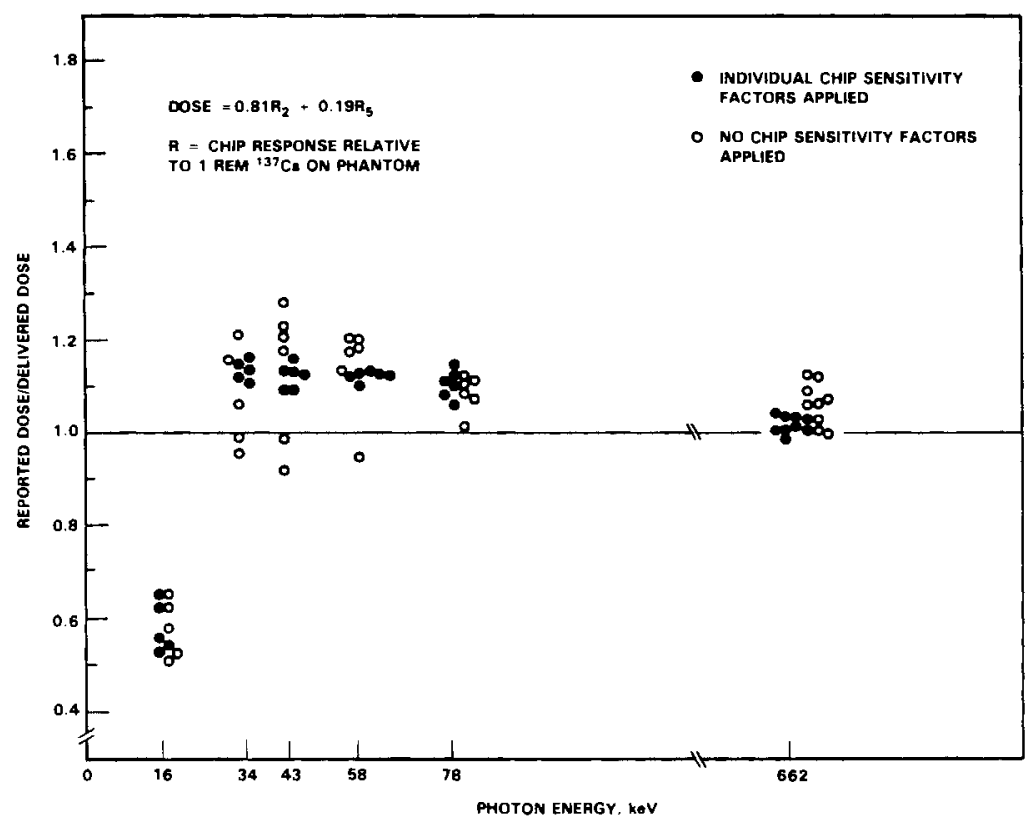

FIGURE 6.5. Comparison of Delivered and Calculated Deep Dose Using Improved Algorithm for Original and Revised Chip Signals Based on Individual Chip Sensitivity Factors 
To implement this change the current computerized dose algorithm would be changed. The numerical value of the coefficients should stay relatively constant, but the routine processing data should be examined to determine the longterm stability of chip signal in reader units versus the chip dose in mrem.

ANSI N13.11

The proposed performance test for personnel dosimeter processors (ANSI 1982) uses a criterion based on adding the bias and standard deviation for each of the eight categories included in the test. The test categories, dose ranges, and tolerance level are shown in Table 6.1. The performance criterion is

$$
|B|+S \leq L
$$

where $B$ and $S$ designate, respectively, the bias and standard deviation of the following defined performance quotient $(P)$ for a particular category and $L$ is the tolerance level for deep or shallow dose equivalents as shown in Table 6.1. The performance quotient for each dosimeter $i$ is defined as

$$
P_{i}=(\text { Reported Dose - Given Dose)/Given Dose }
$$

and values of $B$ and $S$ are determined from

$$
B=(1 / N) \sum_{i=1}^{N} P_{i}
$$

and

$$
S=\left[\frac{\sum_{i=1}^{N}\left(P_{j}-\bar{P}\right)^{2}}{N-1}\right]^{\frac{1}{2}}
$$

A total of 15 dosimeters are included in each category.

It is apparent from Figures 6.2 and 6.3 that the current Hanford dosimeter using current read out, calibration, and dose algorithm procedures would not assuredly pass categories III and IV and may have difficulty with categories $V$ and VII if care is not taken with the beta calibration used in the dosimeter evaluations (see Figure 6.1). 
TABLE 6.1. ANSI N13.11 Test Categories (ANSI 1982)

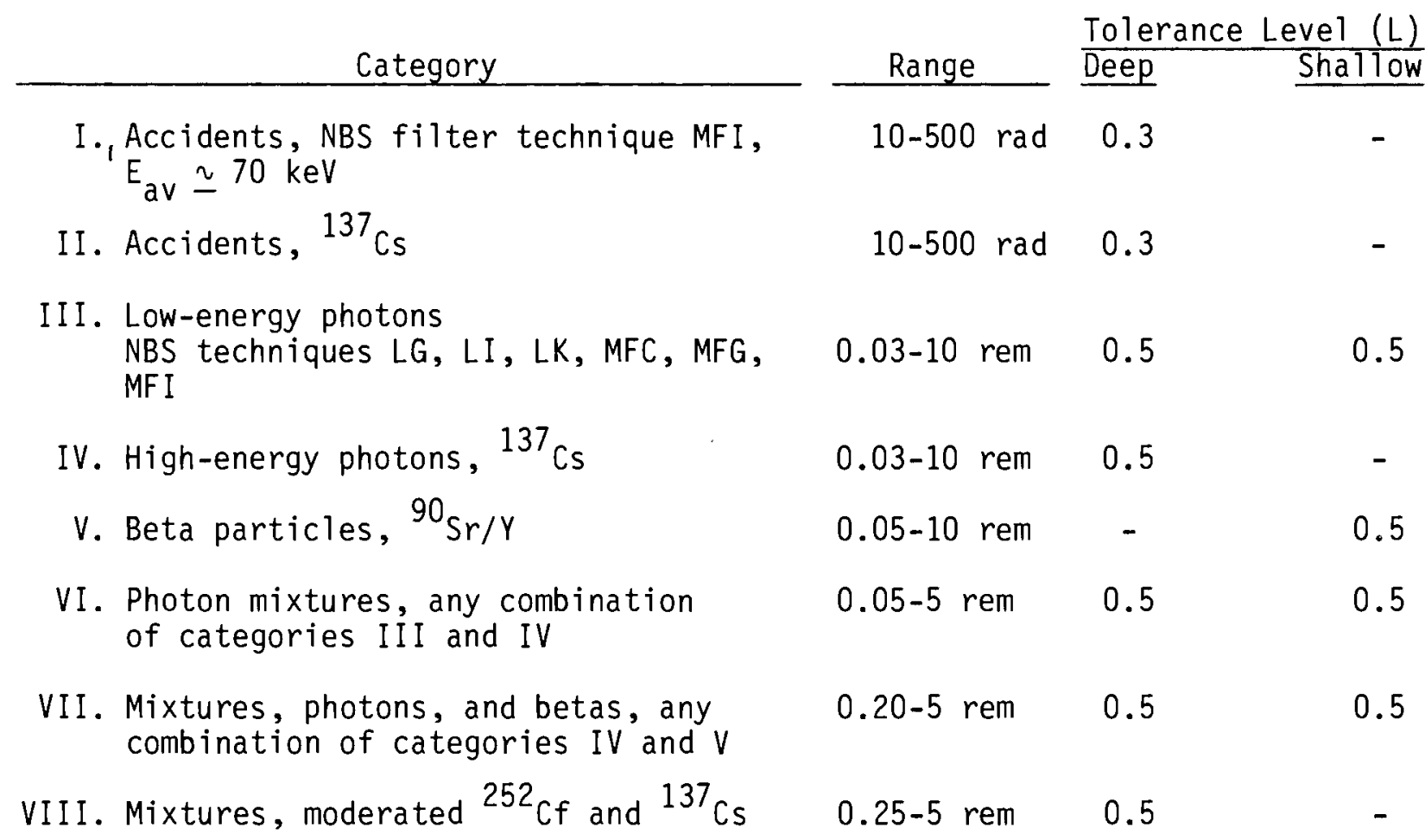

A summary showing expected performance with the ANSI N13.11 for each of the foregoing sections is presented in Table 6.2 for K-fluorescent $x$ rays, ${ }^{137} \mathrm{Cs}$, and ${ }^{90} \mathrm{Sr} / \mathrm{Y}$ irradiations. Evaluation of the dosimeter response using $K$-fluorescent $x$ rays was desired as compared to the filtered $x$ rays specified in the ANSI standard because the monoenergetic techniques provide a better representation of dosimeter energy dependence. The dosimeter performance would be expected to improve using the filtered x-ray techniques specified in the standard. It is apparent from this table that the chip sensitivity factors generally reduce the observed variability and the improved algorithm reduces the observed bias. The combination of chip sensitivity factors and improved algorithm significantly improves the overall system performance. Table 6.1 as we11 as Figures 6.2 through 6.5 provide a basis for comparison for the modified dosimeter options which follow. 
TABLE 6.2. Expected Performance of Current Dosimeter Options Relative to ANSI N13.11 Criteria

\begin{tabular}{|c|c|c|c|c|c|c|c|c|c|}
\hline \multirow[b]{2}{*}{ Photon Energy } & \multicolumn{3}{|c|}{ Current System } & \multicolumn{3}{|c|}{$\begin{array}{c}\text { Current with } \\
\text { Chip Sensitivity } \\
\text { Factors }\end{array}$} & \multicolumn{3}{|c|}{$\begin{array}{c}\text { Improved Algorithm } \\
\text { Plus Chip Sensitiv- } \\
\text { ity Factors }\end{array}$} \\
\hline & $\mathrm{B}$ & $\mathrm{S}$ & $L$ & $\mathrm{~B}$ & $\mathrm{~S}$ & $L$ & $B$ & $\mathrm{~S}$ & $L$ \\
\hline $16 \mathrm{keV}$, shallow & $\begin{array}{r}0.09 \\
-0.43\end{array}$ & $\begin{array}{l}0.14 \\
0.06\end{array}$ & $\begin{array}{l}0.23 \\
0.49\end{array}$ & $\begin{array}{r}0.11 \\
-0.33\end{array}$ & $\begin{array}{l}0.04 \\
0.06\end{array}$ & $\begin{array}{l}0.15 \\
0.39\end{array}$ & $\begin{array}{r}0.02 \\
-0.43\end{array}$ & $\begin{array}{l}0.04 \\
0.02\end{array}$ & $\begin{array}{l}0.06 \\
0.45\end{array}$ \\
\hline $\begin{array}{c}34 \mathrm{keV} \text {, shallow } \\
\text { deep }\end{array}$ & $\begin{array}{l}0.51 \\
0.30\end{array}$ & $\begin{array}{l}0.13 \\
0.13\end{array}$ & $\begin{array}{l}0.64^{*} \\
0.43\end{array}$ & $\begin{array}{l}0.55 \\
0.38\end{array}$ & $\begin{array}{l}0.05 \\
0.01\end{array}$ & $\begin{array}{l}0.60^{\star} \\
0.39\end{array}$ & $\begin{array}{l}0.18 \\
0.13\end{array}$ & $\begin{array}{l}0.04 \\
0.02\end{array}$ & $\begin{array}{l}0.22 \\
0.15\end{array}$ \\
\hline $\begin{array}{l}43 \mathrm{keV} \text {, shallow } \\
\text { deep }\end{array}$ & $\begin{array}{l}0.47 \\
0.36\end{array}$ & $\begin{array}{l}0.19 \\
0.18\end{array}$ & $\begin{array}{l}0.66^{\star} \\
0.54^{\star}\end{array}$ & $\begin{array}{l}0.46 \\
0.35\end{array}$ & $\begin{array}{l}0.04 \\
0.03\end{array}$ & $\begin{array}{l}0.50 \\
0.38\end{array}$ & $\begin{array}{l}0.09 \\
0.12\end{array}$ & $\begin{array}{l}0.03 \\
0.02\end{array}$ & $\begin{array}{l}0.12 \\
0.14\end{array}$ \\
\hline 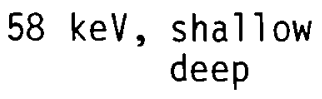 & $\begin{array}{l}0.39 \\
0.37\end{array}$ & $\begin{array}{l}0.16 \\
0.12\end{array}$ & $\begin{array}{l}0.55^{\star} \\
0.49\end{array}$ & $\begin{array}{l}0.38 \\
0.35\end{array}$ & $\begin{array}{l}0.02 \\
0.01\end{array}$ & $\begin{array}{l}0.39 \\
0.36\end{array}$ & $\begin{array}{l}0.01 \\
0.11\end{array}$ & $\begin{array}{l}0.04 \\
0.01\end{array}$ & $\begin{array}{l}0.05 \\
0.12\end{array}$ \\
\hline $\begin{array}{c}78 \mathrm{keV}, \text { shallow } \\
\text { deep }\end{array}$ & $\begin{array}{l}0.28 \\
0.28\end{array}$ & $\begin{array}{l}0.18 \\
0.05\end{array}$ & $\begin{array}{l}0.46 \\
0.33\end{array}$ & $\begin{array}{l}0.03 \\
0.31\end{array}$ & $\begin{array}{l}0.01 \\
0.03\end{array}$ & $\begin{array}{l}0.31 \\
0.34\end{array}$ & $\begin{array}{r}-0.04 \\
0.10\end{array}$ & $\begin{array}{l}0.04 \\
0.02\end{array}$ & $\begin{array}{l}0.08 \\
0.12\end{array}$ \\
\hline${ }^{137} \mathrm{Cs}$, shallow & $\begin{array}{l}0.05 \\
0.04\end{array}$ & $\begin{array}{l}0.06 \\
0.06\end{array}$ & $\begin{array}{l}0.11 \\
0.10\end{array}$ & $\begin{array}{l}0.00 \\
0.00\end{array}$ & $\begin{array}{l}0.03 \\
0.02\end{array}$ & $\begin{array}{l}0.03 \\
0.02\end{array}$ & $\begin{array}{l}0.03 \\
0.02\end{array}$ & $\begin{array}{l}0.03 \\
0.02\end{array}$ & $\begin{array}{l}0.06 \\
0.04\end{array}$ \\
\hline${ }^{90} \mathrm{Sr}$, shallow & & & & & & & -0.39 & 0.02 & 0.41 \\
\hline
\end{tabular}

* Fails category.

MODIFIED HANFORD DOSIMETRY DESIGNS

Several combinations of filters (type and thickness) and phosphors (as discussed in Sections 3.0 and 4.0 ) can be used to provide an improved capability to determine doses for beta-photon radiation. All of these combinations would involve changing the current dosimeter holder and dosimeter card as well as calibration procedures and dose algorithms. A simple dosimeter system modification which would improve the dosimetry capability of the current dosimeter is to remove the security credential. These modifications to the dosimetry system are discussed in the following sections. Dosimeter response following these modifications may be compared to the response for the current dosimeter given in the previous section. 


\section{No Security Credential}

Without the security credential, the filtration over the open window is about $10 \mathrm{mg} / \mathrm{cm}^{2}$ compared to the current filtration of about $90 \mathrm{mg} / \mathrm{cm}^{2}$. This change affects the photon response of the dosimeter very little (Fix 1981, Study 2 Cumings et al.) but significantly improves the capability of the dosimeter with respect to beta radiation. Considering the objective of estimating the shallow dose at a depth of $7 \mathrm{mg} / \mathrm{cm}^{2}$, the assessment of dose is more direct using the dosimeter without a security credential. Also, from examining the response curve in Figure 6.1 for the current dosimeter, it is apparent that the transmission of lower energy beta particles will be substantially less than for the relatively high-energy beta particles used in calibration $\left({ }^{90} \mathrm{Sr} / \mathrm{Y}\right.$ equivalent exposure from U-nat discs) and may result in an underestimate of the shallow dose.

Presently, there is little or no work underway involving low-energy beta radiation as well as there are several operational controls which substantially reduce the shallow dose from beta radiation received by personnel. For example, clothing and gloves worn will significantly reduce the actual dose received from beta radiation.

\section{Modified Dosimeter Designs}

Several modifications of the current dosimeter were examined in Section 4.0 . Two general designs were considered. The first involves using two or more TL phosphors in the dosimeter. Because of the different response characteristics for the phosphors, the dosimeter with proper calibration and algorithms functions as a spectrometer. The most attractive phosphors to combine with the currently used $\mathrm{LiF}$ were $\mathrm{CaSO}_{4}$ and $\mathrm{CaF}_{2}$. However, both of these phosphors were rejected after prototype evaluation for use with the current Hanford system.

The $\mathrm{CaSO}_{4}$ phosphor lacked adequate physical integrity to be routinely processed by the Hanford readers, was affected by the cleaning process, and displayed significant signal fading following irradiation. The $\mathrm{CaF}_{2}$ : Mn phosphor (TLD-400) also has a significant signal fade following irradiation and has a primary higher temperature trap at about $300^{\circ} \mathrm{C}$. This trap is too high to be read with the existing Teflon used in the dosimeter card. The current hot prod temperature of $300^{\circ} \mathrm{C}$ to $310^{\circ} \mathrm{C}$ for 20 seconds significantly affects the practical 
lifetime of the existing dosimeter cards. A higher read temperature would exacerbate this problem. Replacement of the Teflon enclosure has been examined previously (Fix 1982, Study 6 Thorson et a1.) but a significant change in light transfer properties would likely be involved in any significant improvement. The higher temperatures attainable from replacement films are generally unknown.

The second general design considered involved using all LiF phosphors similar to the existing dosimeter. Two very similar dosimeter designs were examined. Both designs involved using four TLD-700 chips and one TLD-600 chip. The difference between the two was the use of a single 15-mil-thick chip in position 1 in one design and the conventional 35-mil-thick chip in the other design. The 15-mil chip corresponds to approximately $100 \mathrm{mg} / \mathrm{cm}^{2}$ as opposed to $231 \mathrm{mg} / \mathrm{cm}^{2}$ for the conventional chip. The attractiveness of the thin chip is its relatively enhanced response to beta radiation (see Table 3.4) compared to the conventional chip while exhibiting the same response to photons. This response can be used to improve the dosimeter's capability for calculating doses from low-energy photons and beta particles. However, this enhanced beta response is not present when the security credential is attached to the front of the dosimeter because of its effective filtration of all low-energy beta particles.

The design of a dosimeter using conventional LiF chip was described in Table 4.5 of Section 4.0. Algorithms for this dosimeter were discussed in Section 5.0. The shallow and deep dose responses of this dosimeter to K-fluorescent and filtered $x$ rays as well as beta particles are shown in Figures 6.6 through 6.8. The beta response was determined without a security credential. The response of this dosimeter can be compared with the response for the current dosimeter (Figures 6.1 through 6.3) and the current dosimeter utilizing individual chip sensitivity factors and improved algorithm in Figures 6.4 and 6.5. It is apparent that the performance of the modified dosimeter is better in terms of both bias and precision than any upgrade of the current dosimeter. This is expected considering that 4 chips are being devoted to determining the betagamma dose as opposed to only 2 chips in the current dosimeter or 3 chips using the improved algorithm. However, the modified dosimeter has very limited capabilities with respect to determining personnel doses from neutrons. The dosimeter does have the same sensitivity to detecting neutrons but does not have the capability to discriminate between thermal and epithermal neutrons. 


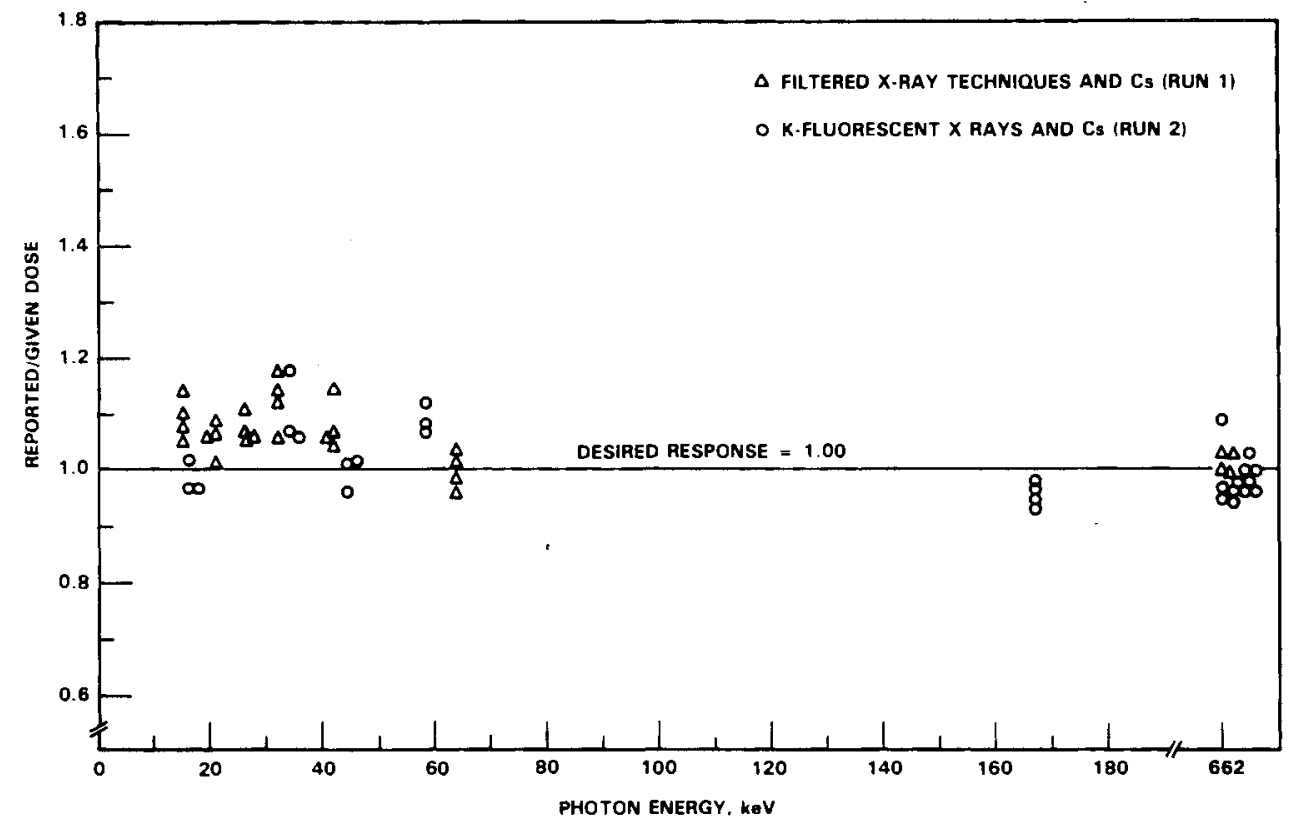

FIGURE 6.6. Modified Dosimeter Shallow Dose Response to K-Fluorescent and Filtered X-Ray Photons

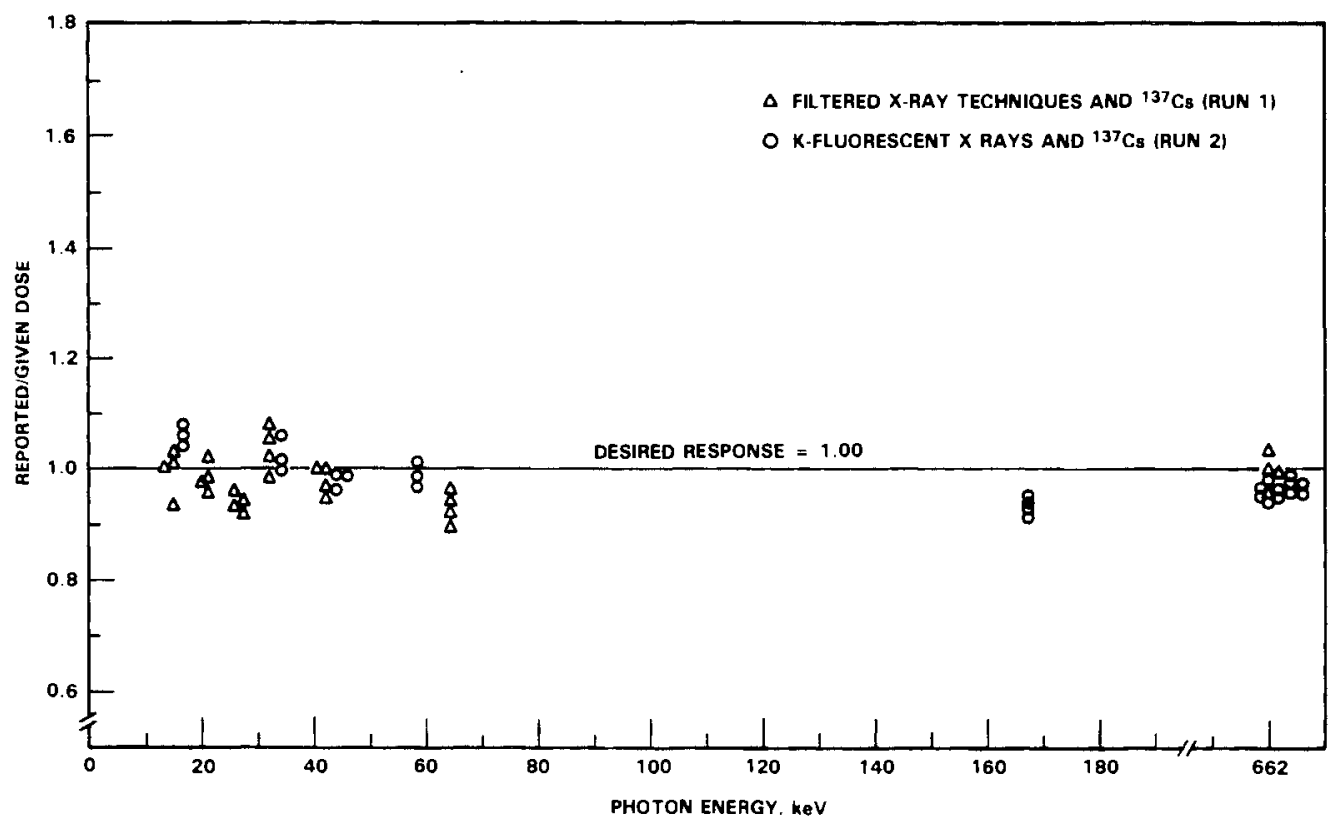

FIGURE 6.7. Modified Dosimeter Deep Dose Response to K-Fluorescent and Filtered X-Ray Photons 


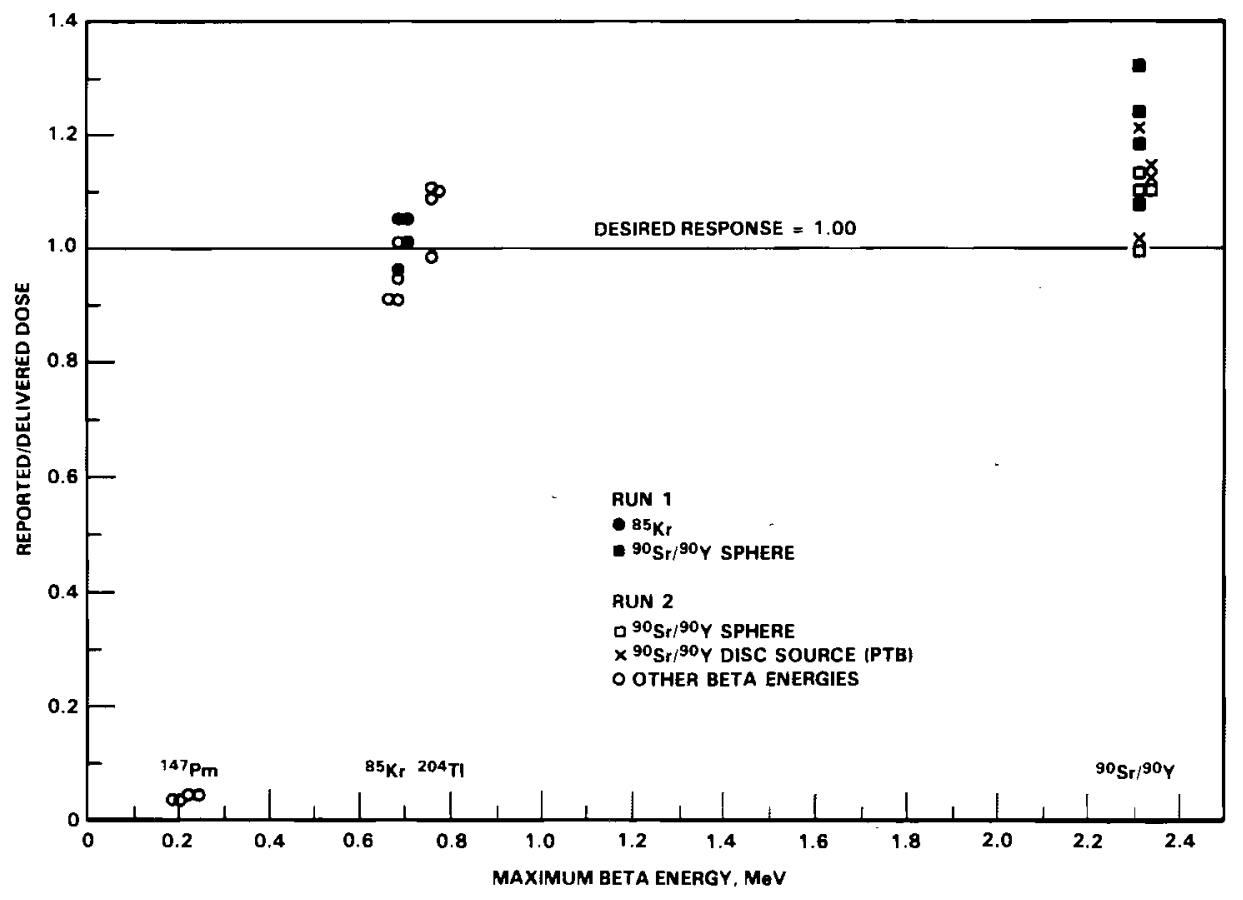

FIGURES 6.8. Modified Dosimeter Response to Selected Beta Emitting Nuclides 


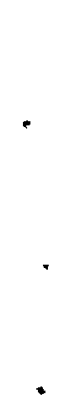




\section{REFERENCES}

American National Standards Institute. 1982. Draft Standard, "Criteria for Testing Personnel Dosimetry Performance." ANSI N13.11. American National Standards Institute, New York, NY.

Brackenbush. L. W., et a1. 1982. "Personnel Neutron Dosimetry at Department of Energy Facilities." PNL-3213, Pacific Northwest Laboratory, Richland, Washington.

Fix, J. J., and M. L. Miller. 1978. "The Hanford Environmental CaF $: M n$ Thermoluminescent Dosimeter." PNL-2489, Pacific Northwest Laboratory, Richland, Washington.

Fix, J. J., et al. 1981a. "Hanford Personnel Dosimeter Supporting Studies FY-1980." PNL-3536, Pacific Northwest Laboratory, Richland, Washington.

Fix, J. J. 1981b. "Eighth DOE Workshop on Personnel Neutron Dosimetry." PNL-SA-9950, Pacific Northwest Laboratory, Richland, Washington.

Fix, J. J., et al. 1982. "Hanford Personnel Dosimeter Supporting Studies FY-1981." PNL-3736, Pacific Northwest Laboratory, Richland, Washington.

Harshaw. 1976. "Harshaw TL Materials and Dosimeters." June, 1976 Brochure. The Harshaw Chemical Company, Solon, Ohio.

Johns, H. E., and J. R. Cunningham. 1969. The Physics of Radiology. Charles Thomas. Springfield, Illinois.

Kocher, L. F., et a1. 1971. "The Hanford Thermoluminescent Multipurpose Dosimeter." BNWL-SA-3955, Pacific Northwest Laboratory, Richland, Washington.

Lakshmanan, A. R., B. Chandra and R. T. Bhatt. 1982. "Thermoluminescence Response Characteristics of $\mathrm{CaF}_{2}: T \mathrm{Tm}$ to $X$ and Gamma Radiations - Evidence for the Presence of 2-Hn Traps." Radiation Protection Dosimetry, 2(1), p. 13-21.

Lasky, J. B., and P. R. Moran. 1977. "TLD-100 Diffused with Boron: A New 'Surface Sensitive' TL Phosphor." Fifth International Conference on Luminescent Dosimetry, p. 122-123.

Mckinley, A. F. 1981. Thermoluminescent Dosimeter." Medical Physics Handbook 5. ISSN-0143-0203. National Radiation Protection Board, Harwell. Published by Adam Holzer, LTD., Bristol, England.

Oberhofer, M., and A. Scharmann. 1979. Applied Thermoluminescent Dosimetry. Published by Adam Holzer, LTD., Bristol, England.

Parkhurst, M. A. 1982. "Ninth DOE Workshop on Personnel Neutron Dosimetry." PNL-SA-10714, Pacific Northwest Laboratory, Richland, Washington. 
Yoder, R. C., et al. 1979. "Confirmation of Conversion Factors Relating Exposure and Dose Equivalent Index Presented in ANSI N13.11," PNL-3219, Pacific Northwest Laboratory, Richland, Washington. 
APPENDIX A

LEAST SQUARES METHOD OF DOSE EVALUATION 


\section{LEAST SQUARES METHOD OF DOSE EVALUATION}

Assume an algorithm of the form:

$$
D=C_{1} R_{1}+C_{2} R_{2}+\ldots+C_{N} R_{N}
$$

where $D$ is the reported dose, $N$ is the number of dosimeter positions used to evaluate dose, $R_{i}$ is the response of a dosimeter position $i$, in rem, relative to a ${ }^{137} \mathrm{Cs}$ calibration, and $C_{j}$ is a constant for each dosimeter position. The following analysis can be used to solve for all values of $C$ after exposure to a range of calibration energies. A separate set of constants is obtained for each depth of interest in tissue.

The error in calculating dose for a 1-rem exposure to any energy $E$ is given by

$$
X(E)=C_{1} R_{2}(E)+C_{2} R_{2}(E)+\ldots+C_{N} R_{N}(E)-1
$$

For irradiations to several calibration energies, the total error is obtained by summing over all test energies. Following the usual procedure for a least squares analysis, the error term is squared and the partial derivative with respect to each $C_{i}$ is set equal to zero. The following system of equations is obtained.

$$
\begin{aligned}
& 0=\sum_{k}\left\{R_{1}(E) \cdot\left[C_{1} R_{1}(E)+C_{2} R_{2}(E)+\ldots+C_{N} R_{N}(E)-1\right]\right\} \\
& 0=\sum_{k}\left\{R_{2}(E) \cdot\left[C_{1} R_{1}(E)+C_{2} R_{2}(E)+\ldots+C_{N} R_{N}(E)-1\right]\right\} \\
& 0=\sum_{k}\left\{R_{N}(E) \cdot\left[C_{1} R_{1}(E)+C_{2} R_{2}(E)+\ldots+C_{N} R_{N}(E)-1\right]\right\}
\end{aligned}
$$

for each calibration energy $k$. 
Solving the equations will yield an algorithm that minimizes the error in the calculated dose for all calibration energies. Another constraint must be added. For ${ }^{137} \mathrm{Cs}$, the shallow and deep dose response of each position, $R_{j}$, is equal to unity. To calculate the delivered dose from ${ }^{137} \mathrm{Cs}$ correctly, the sum of all coefficients must be equal to one.

$$
1=c_{1}+c_{2}+\ldots+c_{N}
$$

Therefore, one of the coefficients may be determined from the other values of $C$, and the number of unknowns is reduced by one. If the term $\left[1-\left(C_{2}+C_{3}\right.\right.$ $\left.\left.+\ldots+C_{N}\right)\right]$ is substituted for $C_{1}$, the equations take the form

$$
\begin{aligned}
0= & \Sigma\left\{C_{2}\left[R_{2}(E)-R_{1}(E)\right] \cdot R_{i}(E)+C_{3}\left[R_{3}(E)-R_{1}(E)\right] \cdot R_{i}(E)+\ldots+\right. \\
& \left.C_{N}\left[R_{N}(E)-R_{1}(E)\right] \cdot R_{i}(E)+\left[R_{1}(E)-1\right] \cdot R_{i}(E)\right\} \\
i= & 2,3 \ldots N
\end{aligned}
$$

Chip responses are summed over all calibration energies and substituted into the equations. The equations can be arranged for matrix solution if desired.

For a three-element system, the system for all calibration energies reduces to:

$$
\begin{aligned}
& 0=C_{2} \sum_{k}\left\{\left[R_{2}(E)-R_{1}(E)\right] \cdot R_{2}(E)\right\}+C_{3} \sum_{k}\left\{\left[R_{3}(E)-R_{1}(E)\right] \cdot R_{2}(E)\right\}+ \\
& \sum_{k}\left\{\left[R_{1}(E)-1\right] \cdot R_{2}(E)\right\} \\
& \left.0=C_{2} \sum_{k}\left\{\left[R_{2}(E)-R_{1}(E)\right] \cdot R_{3}(E)\right\}+C_{3} \sum_{k}\left\{L R_{3}(E)-R_{1}(E)\right] \cdot R_{3}(E)\right\}+ \\
& \sum_{k}\left\{\left[R_{1}(E)-1\right] \cdot R_{3}(E)\right\} \\
& C_{1}=1-C_{2}-C_{3}
\end{aligned}
$$


For the 2-element photon deep dose calculation in Section 5.0, the equations are simpler:

$$
\begin{aligned}
& C_{2}=\frac{\sum_{k} R_{2}(E)-\sum_{k}\left[R_{1}(E) \cdot R_{2}(E)\right]}{\sum_{k}\left[R_{2}(E)\right]^{2}-\sum_{k}\left[R_{1}(E) \cdot R_{2}(E)\right]} \\
& C_{1}=1-C_{2} .
\end{aligned}
$$




\section{DISTRIBUTION}

No. of

Copies

OFFSITE

$$
\begin{aligned}
& \text { E. J. Vallario } \\
& \text { Assistant Chief/Manager } \\
& \text { Health Physics Programs } \\
& \text { Office of Nuclear Safety } \\
& \text { U.S. Department of Energy } \\
& \text { Washington, DC } 20545 \\
& \text { W. V. Baumgartner } \\
& \text { U.S. Testing Company } \\
& 2800 \text { George Washington Way } \\
& \text { Richland, WA } 99352
\end{aligned}
$$

S. A. Davis

U.S. Testing Company

2800 George Washington Way

Richland, WA 99352

27 DOE Technical Information Center

\section{ONSITE}

6 DOE Richland Operations Office

D. R. Elle

R. E. Gerton

H. E. Ransom

M. W. Tiernan

G. R. Yesberger (2)

4 Rockwell Hanford Operations

W. A. Decker

B. E. Knight

P. G. Lorenzini

D. Paine
No. of

Copies

3 UNC Nuclear Industries

P. A. Carlson

D. S. Cunningham

W. G. Westover

1 Hanford Engineering Development Laboratory

G. D. Carpenter

36 Pacific Northwest Laboratory

F. M. Cummings

F. N. Eichner

G. W. R. Endres

T. H. Essig

L. G. Faust

J. J. Fix (5)

W. A. Glass

G. R. Hoenes

K. L. Holbrook

J. J. Houston

J. J. Jech (7)

R. L. Kathren

H. V. Larson

P. L. Roberson

K. L. Soldat

C. M. Unruh

R. H. Wilson

M. K. Winegardner

Health Physics Technology Library

Technical Information Library (5)

Publishing Coordination (2) 
